NBER WORKING PAPER SERIES

CREDIBILITY, REAL INTEREST

RATES, AND THE OPTIMAL SPEED

OF TRADE LIBERALIZATION

Kenneth A. Froot

Working Paper No. 2358

NATIONAL BUREAU OF ECONOMIC RESEARCH

1050 Massachusetts Avenue

Cambridge, MA 02138

August 1987

The research reported here is part of the NBER's research program in International Studies. Any opinions expressed are those of the author and not those of the National Bureau of Economic Research. 


\section{$\underline{\text { ABSTRACT }}$}

This paper investigates the effects of imperfectly reclible trade liberalization programs on welfare and the allocation of real resources. Wr prescut a rational expectations model in which a government with limited acress to intermational funnrial markets may be forced to abort a liberalization program if hard-currency reserves are depleted too quickly. The liberalization's lack of perfect credibility arts as a distortion which becomes (rationally) intensified under the typical first-best policy of a direct move to free tracke. A gradual lowering of trade barriers turns out to be welfare-supcrion to an immedinte liberalization, and to improve the chance that. the program will ultimately sucreed. We then derive the optimal speed of liberalization, the intertemporal allocation of resmurces, and the libcralization progran's credibility.

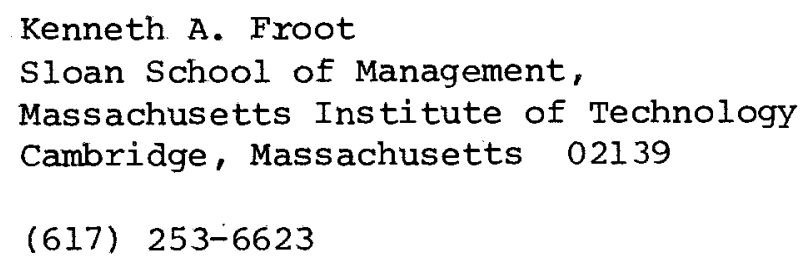




\title{
Credibility, Real Interest Rates, and the Optimal Speed of Trade Liberalization
}

\author{
Kemeth A. Front. \\ Sloan School of Managenent, \\ Massachusetts Institute of Technology \\ Cambridge, Massachusetts (02139
}

Given the unpopularity of tariffs annong economists, it shomld come as no sumprise that so many countries have been counselled to embark upon ambitions trade liberalization programs over the past decade. In return for large reductions in trade barriers, conventional neo-classical models and newer models using an intertemporal approach to commercial policy offer the prospect of improvements in welfare and efficiency. To the extcnt that these models are realistic, they make a strong case for the viability and profitability of immerliate and complete trade liberalization.

In an uncertain world, however, there is less canse for optimism than many such models would suggest. Recent attempts at trade liberalization in the soutthe'n cone of Latin America, like many earlier programs in these and other comtrics, have becn completely or (as in the case of Chile) partially abandoned. Argentina and Un'uguay, for example, had plans to establish a lower, more uniform tariff structure with a maximum rate of 35 percent (down from several hundred percent) and a minimum rate of about 10 percent. The Argentinian package, annonnecd in December 1978, was abandoned in 1981 and the progress that had becn made was soon reversed. The Uniguayan plan never succeeded in reducing trade barricrs. Chile was by far the most successful in bringing down tariffs, which reached a miform level of 10 pereent (excluding autos) by the end of 1979. Since then, however, tariffs have becn raised substantially.

With this kind of experience as the mule, it scems our models should arderess the possibility that agents will take the government's stated intention of permanently libcralizing trade with a (rational) grain of salt. Several authors have in fact argued that recent trade libcralization programs in the southern cone were not fully credible. Edwards (1084, 1985), Pastore (1982), Sjaasted (1983), and Dornbusch (1984), for example, all point toward blatant domestic policy inconsistencies as being 
partly responsible for the programs' failures. ${ }^{1}$ Notwithstanding this conscnsus, however, there has been little attempt to investigate the mechanisms hy which a lack of credibility actually makes failure more likely.

This paper represents a more formal attempt to inject the issue of imperfectly credible government policy into the discussion of tariff reduction. We investigate the intertemporal incentives in consumption and the distortions in output which are generated by fears that the liberalization program will be short lived. In addition, we try to rank explicitly commercial policy alternatives by their effects on welfare, the allocation of real resources, and the level of credibility. The analysis intentionally focuses on countries (sucl as many LDC's torlay) which have limited access to international financial markets, in the sense that manticipated current account deficits must be financed by reserve depletion instead of by borrowing. The credibility of trade reform is perlaps most important in these countries because of their dual histories of policy reversals and severe trade restrictions.

Our interest lies not just in how doubts about the permanence of trade reforms contribute to the eventual reinstatement of trade barricrs. We also consider the effects of altemative, slower speeds of liberalization on the equilibrium level of credibility. Even though such slower rates of reform are second-best in that they represent clear deviations from the neoclassical optimum, they are desirable here because they turn out to lessen the distortion cenerated by the lack of perfect credibility. Indeed, it turns out that in the nodel below, governments with credibility problems should not pursue policies that eliminate tariffs right away. Such a finding is particularly surprising in the context of our optimizing two-period franework, which tends to bias the results toward complete and instantancous liberalization even as compared with more standard macro-economic treatments. ${ }^{2}$ In the modern intertemporal approach, for cxample. a permancent tariff reduction is painless in the sense that it does not result in a trarle deficit. Onec tariffs are zero, there is no intertemporal incentive to deviate from the neclassical optimum of halanced trade. ${ }^{3}$

The simple two-period nodel below treats a country which has recently removed its trade

\footnotetext{
${ }^{1}$ Dornbusch (1984), in particular alludes to the intertemporal effects generated ly expectations of higluer future tariffs.

${ }^{2}$ Examples of the approarh used in this paper include Dixit and Norman (1980). Siensson and Razin (1983), Razin and Svensson (1983), Edwards and van Wijnl)ergen (1983), and van Wijuliergen (1984).

${ }^{3}$ As van Wijnbergen (1983) points ont, tariff reductions in LDC's may inply an alsolute decline in the return to capital, since imports in those countries are often relatively capital intensive. In the intertemporal alproach. removing tarifs once and for all could then reduce investment, leading to an improvement in the current account.
} 
restrictions, so that tariffs are zero in the first period. If agents believe that the government may be forced to abandon the liberalization in period two, consumers are inclined to substitute consumption toward the first period and produccrs will on average divert morc resources toward the inefficient import sector. These two sources of additional spending lead to a current account deficit, which in turn will make the government more susceptible to cxternal shocks that deplete reserves. A higher percentage of the time, the anthorities will be forced to levy tariffs in an effort to cut imports, thereby generating badly necled hard-currency reserves. In this way, agents' disbelief that the policy will endure becornes sclf-fulfilling.

After describing the model in section 1, section 2 goes on to derive a rational expectations equilibrium in which the current account deficit, level of welfare, and the probability of collapse are endogenous. Next, we consider a more gradual liberalization progran which employs positive first-period tariffs. It is possible to show that gradualism improves welfare, lowers the current account deficit, and raises the probability that free trade will ultimatcly prevail. There is a unique, positive first-period tariff which is welfarc optimal.

For many developing countries today, particularly those with large external debts, binding restrictions on international borrowing and the scarcity of hard-currency rescrves fix current accounts more or less exogenously. In section 4, the effects of imperfect credibility are investigated when consumers cannot substitute toward current consumption by ruming a larger current account deficit. ${ }^{4}$ In these circumstances, the shadow value of saving must increase to equilibrate the expected marginal utility of real consumption in both periods. High renl interest rates have in fact been a common feature of many recent liberalization attempts. Here we find that more gradual speeds of liberalization will help bring down interest rates and shift production toward the export sector. Finally, section 5 concludes.

\section{The Model}

We employ a two-period model of a small country similar to that of Svensson and Razin (1983), Razin and Svensson (1982), and Edwards and van Wijnbergen (1983). There are two goods, exports $(x)$ and imports $(m)$, both of which are consumed and produced. The sunall country is represented

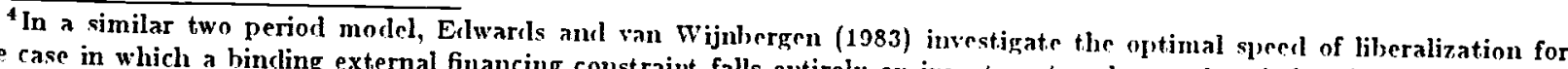
the case in which a hinding external financing constraint falls entirely on investment and seconcl-periot tariffs are zero with
certainty.
} 
by a single consumer, who maximizes expected welfare, $W=W(\gamma, \Gamma)$, where $\gamma=\gamma\left(c_{m}, c_{x}\right)$ denotes subutility in period one of the consumption of imports. $c_{m}$, and cxports, $c_{x}$. Period two subutility is expressed as $\Gamma=\Gamma\left(C_{m}, C_{x}\right) .^{5} \gamma$ and $\Gamma$ are assumed to have the expected utility property and are homothetic. Without loss of generality, $\gamma$ and $\Gamma$ can be chosen to be lincarly homogeneous. Each period's expected subutility has an associated unit expcnditure function, $\pi$ and $\Pi$, which yields the minimum expenditure required to reach the unit level of expected subutility in that period, given current prices of imports and exports:

$$
\begin{gathered}
\pi\left(p_{m}, p_{x}, 1\right)=\min \left\{p_{m} c_{m}+p_{r} c_{r}: 1 \leq \gamma\left(c_{m}, c_{r}\right)\right\}, \\
\Pi\left(P_{m}, P_{x}, 1\right)=\min \left\{P_{m} C_{m}+P_{r}\left(c_{x}: 1 \leq \Gamma\left(C_{m}, C_{r}\right)\right\} .\right.
\end{gathered}
$$

We can think of $\pi$ and $\Pi$ as the price of obtaining a single mit of expected subutility in that period or as the price of a unit of real spending, $\gamma$. $\Gamma$. Expressions for nominal spending are therefore $\pi \gamma$ and $\Pi \Gamma$, the price index times the measure of real comsumption in that period.

The analogous intertemporal expenditure function, $E(\pi, D \Pi, W)$, gives the minimum present discomited expenditure recuired to achieve a fixed level of expected welfare, for given levels of the price indexes, $\pi$ and $\Pi$ :

$$
E(\pi, D \Pi, W)=\min \left\{\pi\left(p_{m}, p_{r}\right) \gamma+D \Pi\left(P_{m}, P_{r}\right) \Gamma: \tilde{W} \leq W(\gamma, \Gamma)\right\}
$$

where $D=\frac{1}{1+i}$ is the discount factor and $i$ is the domestic nominal interest rate. Overall welfare, $W$, is the expected utility of real consumption over both periods.

We will use the well-known properties of the expenditure fuuction that its first derivative with respect to prices yields the Hicksian compensated demand function for cacl good (here given for period one goods and imports, respectively):

$$
\begin{gathered}
E_{1}(\pi, D \Pi, W)=\gamma(\pi . D \Pi . W) \\
\pi_{m}=\frac{c_{m}\left(p_{m}, p_{r}\right)}{\gamma}
\end{gathered}
$$

\footnotetext{
${ }^{5}$ Throughout the paper we use lower case letters for period one variables aul upper case letters for period two variables.
} 
From the Slutsky equation, the marginal propensity to spend times the clange in expenditure with respect to welfare is equal to the sccond derivative of the expenditure function with respect to price and welfare:

$$
\frac{E_{1 \mathrm{~W}}}{E_{\mathrm{W}}}=\frac{\partial \gamma}{\partial E}=c_{\mathrm{T}}
$$

where $c_{\mathrm{W}}$ is the marginal propensity to spend in period one out of a rhange in expenditure.

On the production side we define first- and sccond-periorl composite revenue functions (over exports and imports), $q$ and $Q$, which are homogeneous of degree one in each period's prices:

$$
q\left(p_{m}, p_{r} ; K, L\right)=\max \left\{p_{m} q_{1}+p_{r} q_{2}: q_{1}, q_{2} \text { arc feasible }\right\}
$$

where the own derivatives with respect to prices, $q_{1}=q_{1}\left(p_{m}, p_{, r} ; K, L\right)$ and $q_{2}=q_{2}\left(p_{m}, p_{x} ; K, L\right)$ are the first-period supply functions for imports and exports, respectively (and similarly for period two).

\section{Expected Collapse of a Liberalization Program when Reserves are not Rationed}

With this model in mind we consider a comtry which has just liberalized its trade account by eliminating tariffs on imports. In order to focus on the problems LDC's may face during such liberalizations, we assume that the country is credit constraiued in that the private sector does not have direct access to to suppliers of foreign cxchange. Instead, all borrowing in international capital markets is conducted by the goverument at the be gimning of period one. The initial level of hard-currency reserves held by the govermment, $R$, inclurles any external financing the government has been able to arrange, and is treated lere as exogenously determined (though in reality it is the outcome of a quasi-market bargaining process between the government and its creditors).

In these circumstances, the government must finance any current account. deficit from its stock of reserves. (In the next scction, we consider the case in which the government refuses or is umable to finance the cutire current account deficit, and rations forcimn cxclunge instcad.) The government's reserves are also used to shield the private sector from unanticipated shocks to export revenues or import expenditures which occur during period one. Thus the ex post current account deficit, or the total reduction in government reserves, is the sum of the current ancount cleficit the private sector chooses plus a random shock componcnt:

$$
\tilde{z}=z+\mu
$$


where $\mu$ is distributed normally with mean 0 and variance $\sigma_{\mu}^{2}$. At the cul of the first period, reserves are $R-\tilde{z}$.

To focus on the possibility that the liberalization progran will be albandoncd, we assume the government follows a rule-of-thumb policy in reciding whether to impose second-period tariffs. The rule is that tariffs will be reimposed at their original pre-libcralization level in period two if reserves at the end of the first period fall below some critical foor, $R_{\min }$ :

$$
R-\dot{z}<R_{m i n}
$$

Tariffs remain at zero if equation (2) is not satisfied. The probability that the liberalization program will be reversed is just the probability that cquation (2) holds:

$$
\lambda=P\left(R_{m i n}, \sigma_{\mu}^{2}, z\right)=\text { probability }\left\{\mu>R-R_{m i n}-z\right\}
$$

To keep matters simple and to avoid ambiguitics, we assume that $R_{\min }$ is set cenal to the difference between the initial level of reserves and the maximnm current accomnt deficit, i.e., the deficit the private sector would choose if tariffs were to be reinstated with probability one:

$$
R_{\min } \equiv z(\lambda=1)
$$

Notice that even with a balanced current accomnt, there is still a nonzero probability of reversal since:

$$
\lambda=P\left(R_{\min }, \sigma_{\mu}^{2}, z\right)=\text { probability }\left\{\mu>R-R_{\min }\right\}>0 .
$$

The goverment's decision rule implies that the price of imports in period two is distributed binomially:

$$
\tilde{P}_{m}= \begin{cases}p_{m}^{*}, & \text { if } \mu \leq R-R_{m i n}-z ; \\ p_{m}^{*}+\tau_{p}, & \text { if } \mu>R-R_{m i n}-z:\end{cases}
$$

where $\tau_{p}$ is the tariff which will be imposed if the liberalization program fails. In the following analysis, we take $\tau_{p}$ to be given exogenomsly.

Before we proceed, two other aspects of the model recuire claboration. First, in this type of welfare-based general equilibrium morlel, it is often useful to limit the absolute magnitude of distortions (in our case, $\tau_{p}$ ). Large distortions result in large reductions in roal income, and these income effects eventually swamp the subtler substitution effects we wish to sturly. So, for cxample, 
a small tariff in the initial period encourages agents to shift real cxpenditure towards the second period, when the tariff will be removed. As we might cxpect, the current account in period one shows a surplus. In an attrmpt to offect the negative first-period welfare effects of a somewhat. larger temporary tariff, however, agents begin to shift real income back toward the period of the distortion. Utimately, when the tariff grows big cnongh, the additional borrowing in the first period is sufficient to swing the current account into deficit. Althongh one conld question the importance of such perverse marshallian effects on the basis of their doubtful realism, we rule them out here simply because tariffs are imposed by governments with the intention of improving (and not worsening) the current account. We do not wish to consider policies that have effects systematically opposite those expected by the anthorities. Therefore. in the spirit of the small (but finite) tariff assumption, we frequently express sufficient conditions for the paper's results in terms of upper bounds on the size of the tariff.

A second aspect of the model that requires additional explanation is the treatment of uncertainty. Random prices are not usually added to intertemporal general erpilibrium models because of the additional complexity they bring. The standard results from diality theory do not generally hold when prices are random. For example, there is no guarantere that the matrix of Hicksian substitution terms is negative semidefinite. In the present paper, however, we are able to invoke a kind of weak-form certainty equivalence by exploiting the binomial ristribution of import prices and the limitations imposed on the magnitude of the tariff by the small tariff assumption. The intuition for this strategy is actually a simple one. Notice that the nth moment of the second-period tariff, $\tilde{\tau}$, can be written as $M_{n}(\tilde{\tau})=\tau_{p}^{\prime \prime} \lambda\left(1-\lambda^{n-1}\right)$. For small tariffs and any given probability that the liberalization will collapse, the higher-order monents of $\dot{\tau}$ are insignifieantly small relative to the expectation, $\lambda \tau_{p}$. More preciscly:

$$
\lim _{\tau_{p} \rightarrow 0} \frac{M_{n}(\tilde{\tau})}{E(\tilde{\tau})}=\left(1-\lambda^{n-1}\right) \tau_{p}^{n-1}=0, \quad \forall n \geq 2 .
$$

The effects of a change in the probubility that tariffs will be kevied in period two can be made arbitrarily close to the effects of a known change in the future tariff. For small cnough values of $\tau_{p}$, the signs of the substitution and income effects remain the same as in the certainty case, even though the optimal choice variables become vastly more complex functions of the underlying utility and production functions. Since we make no attempt in the paper to specify the varions 
clasticities of consumption and production heyond their repsective signs, all of the results remain general cnough to apply to a variety of utility and production functions. Indeed, such a treatment of uncertainty seems particularly natural in this case, since, as we have already noted, it is desirable to restrict our attention to small values of $\tau_{p}$, even without introducing uncertainty. In the first appendix, we discuss this strategy for dealing with random future tariffs in more detail. We also demonstrate how a restriction on the size of $\tau_{p}$ is sufficient to guarantec that the pure substitution effects (i.e. second derivatives of the expenditure function with respect to expected prices) have the usual signs.

We are now ready to apply the model of the previous scction, and to derive the rationally expected level of credibility, the corresponding current account, and the level of welfare under complete liberalization. The intertemporal budget constraint of the country is:

$$
E\left(\pi\left(p_{m}, p_{x}\right), D \Pi\left(P_{m}, \Gamma_{x}\right), W\right)=q\left(p_{m}, p_{x}\right)+D Q\left(P_{m}, P_{r}\right)+T
$$

Equation (8) requires that total expenditure is equal to the present discounted value of income plus tax revenues. Revenues generated by a future tariff will be retmmed to the private sector in the form of a lump sum transfer, $T$, where

$$
T=D \bar{\tau}\left(E_{2} \Pi_{1}-Q_{1}\right)=D \bar{\tau}\left(C_{m}-Q_{1}\right)
$$

$C_{m}-Q_{1}$ represents net imports, or comsumption minus domestic production of the imported good, and $\bar{\tau}=\lambda \tau_{p}$, the expected future tariff. We assume that the comtry has no prior debt to the rest of the world (this conld easily be added). Consecquently, the cument account deficit is equal to consumption expenditure minus total revenues from production:

$$
z=E_{1} \pi-q
$$

To see that an imperfectly credible commitment to free trade leals to a suboptimal allocation of resources, we take the derivative of ecpuation (8) with respect to $\lambda$ and use ecpuation (9) to get:

$$
E_{\uparrow\rceil} \cdot d W=\lambda \alpha_{0} d \lambda
$$

where

$$
\alpha_{0}=\frac{\tau_{p} D\left(E_{2} \Pi_{11}+\Pi_{1} E_{22} \Pi_{1} D-Q_{1}\right)}{1-\bar{\tau} D \Pi_{1} C_{1}}<0
$$


Equation (11) gives the loss in welfare attributable to a non\%ero probability that future tariffs will be levied. Welfare declines proportionally in the probability of a policy reversal; indeed, integration of equation (11) gives the familiar Harberger result that the loss in welfare is proportional to the square of the distortion (i.e., the lack of perfect credibility).

The welfare effects of the misallocation of resoures are summarized in $\alpha_{0}$. The mumerator is proportional to the discounted substitution effect in consumption and production, holding welfare constant. The first term in the mumcrator, $E_{2} \Pi_{11}=\frac{\partial C_{m}}{\partial \Gamma_{m}}$. is the change in the compensated demand for period two imports from a change in price holding real period two expenditure constant. This captures the intratemporal substitution in consumption of exports for imports. The second term, $\Pi_{1} E_{22} \Pi_{1} D=\frac{C_{m}}{\Gamma} \frac{\partial \Gamma}{\partial P_{m}}$, is the change in period two real spencling from a change in the price of imports, weighted by the share of imports in spending. This term represents the transfer of real income across periods in response to price changes. The thirel term. $-Q_{1}$, is the negative valuation effect on imports realized as a result of the distortion. Taken torecther these three terms comprise the compensated substitution effects of the expected future tariff: all represent welfare losses. ${ }^{6}$

It is worth mentioning the effects on production as well. On the margin, ontput of the imported good is expected to rise by $\Gamma_{m} Q_{11}$ while output. of exports is expected to fall by an equivalent amount, ${ }^{7} P_{x} Q_{21}$. The standard mechanism linking the output of inports and exports is the wagerental ratio, $\omega$, which decreases with higher import prices. The effect of expected price changes on the composition of output can be secn in Figure 1, the familiar Samulson diagram. With zero expected future tariffs, the terms of trade stand at $p$. corresponding to an output mix at point $B$ (where A represents complete specialization in cxports and D represents complete specialization in imports), given the capital-labor ration of the economy, $k$. An increase in tariffs lowers the expected terms of trade to $p^{\prime}$, lowers $\omega$ and moves the output mix to point (\%, where more inuports and fewer exports are produced than before.

\footnotetext{
${ }^{6}$ The overall effect of the expecterl fitture

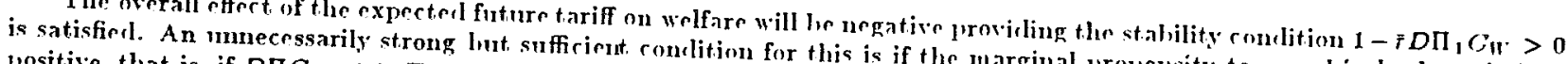

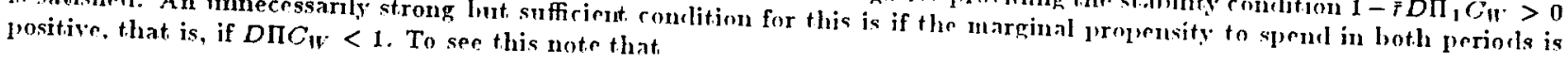$$
F D \Pi_{1} C_{n}=\left(\frac{\bar{r} C_{m}}{\Pi \Gamma}\right) D \Pi C_{n}<\frac{\tilde{r} C_{m}}{\Pi \Gamma}<\frac{\Gamma_{m} C_{m}}{\Pi \Gamma}<1
$$
These two terms cancel exactly only for infinitesimal changes in relative priess. For discreter changes, the change in total
outpht is zero only for first orcler approximations.
} 
Figure 1

The Effects of Expected Future Tariffs on the Expected Period Two Output Mix

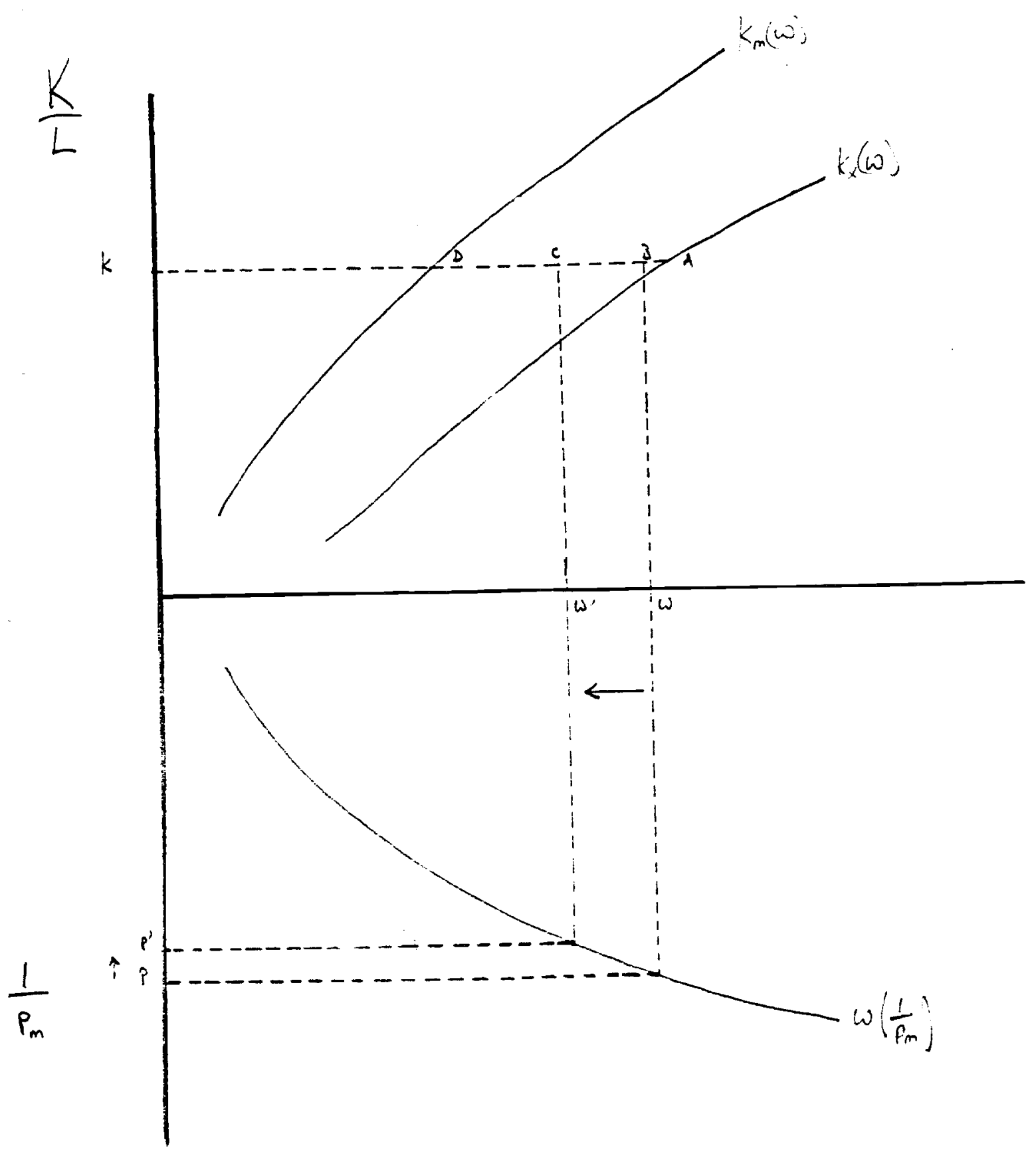


To see the effects of a change in the probability of a policy reversal on the current account we differentiate equation (10) and use equation (11) to get:

$$
\frac{d z}{d \lambda}=\alpha_{1}-\alpha_{2} \lambda
$$

where

$$
\begin{aligned}
& \alpha_{1}=\pi E_{12} \Pi_{1} D>0 \\
& \alpha_{2}=-\pi c_{\Pi} \alpha_{0}>0 .
\end{aligned}
$$

The first term in equation (12), $\alpha_{1}$, is the sum of the compensated intertemporal substitution effects in consumption; it tends to increase umambiguously the curent account deficit. The intuition is that higher expected tariffs raise the aggregate level of prices in the second period and lower the real consumption rate of interest, $1+r=\frac{\pi}{D \Pi}$. The incentive to save is therefore reduced and consumption is transferred toward the first period. Also, the lower the credibility of the liberalization program, the greater the misallocation of real resources toward the inefficient import sector.

The second term in equation (12), $-\alpha_{2} \lambda$, which is negative, reflects the decrease in total income from the distortion weighted by the marginal propensity to spend in period one and the expected tariff. A decrease in total income reduces real spending in every period, ${ }^{8}$ which improves the current account. Notice that if the tariff becomes too large, the second term will dominate, and the expected future tariff will improve the first-period current account. As we mentioned at the beginning of this section, the negative income effects of large tariffs swamp the substitution effects, and ultimately result in current account balances that are not sensible. We therefore use as an upper bound on the size of the tariff the point at which the substitntion effects are just cancelled out by the income effects: $0<\tau_{p} \leq \frac{\alpha_{1}}{\alpha_{3}}$. Note that at the margin $\lambda=0$, the intertemporal substitution effects, $\alpha_{1}$, induce a marginal current account deficit regardless of the size of $\tau_{p}$.

To find the approximate deviation in the level of the current account from the zero expected tariff equilibrium, we integrate equation (12) to get an expression which is once again approximately

\footnotetext{
${ }^{8}$ Nominal spending will rise less than proportionately in the perion with the tariff. and fall alsolutely in the other period.
} 
a quadratic: ${ }^{9}$

$$
z(\lambda)=\alpha_{1} \lambda-\frac{1}{2} \alpha_{2} \lambda^{2}
$$

Equation (13) is graphed in Figure 2. Given our restriction on $\tau_{p}$, the current account deficit is an increasing function of the probability that the liberalization progran will fail. ${ }^{10}$

We can now solve for the rational expectations ecuilibrium of the model by combining equations (3) and (13). A linear approximation to $\lambda$ in equation (3), is used for the algebraic solution since the cumulative normal distribution is not tractable analytically: ${ }^{11}$

$$
\lambda=P\left(\chi, \sigma_{\mu}^{2}, z\right)=\alpha_{3}+\alpha_{4} z
$$

where

$$
\begin{aligned}
& \alpha_{3}=\alpha_{3}\left(R_{\min }, \sigma_{\mu}^{2}\right): \frac{\partial \alpha_{3}}{\partial R_{\min }}<0 . \frac{\partial \alpha_{3}}{\partial \sigma_{\mu}^{2}}>0 \\
& \alpha_{4}=\alpha_{4}\left(R_{\min }, \sigma_{\mu}^{2}\right): \frac{\partial \alpha_{4}}{\partial R_{\min }}>0 . \frac{\partial \alpha_{4}}{\partial \sigma_{\mu}^{2}}>0 .
\end{aligned}
$$

Equations (3) and (13) now give equilibrium levels of credibility, $\lambda^{*}$, and the current account deficit, $z^{*}$ :

$$
\begin{gathered}
\lambda^{*}=\alpha_{3}+\frac{-1-\alpha_{4}\left(\alpha_{2} \alpha_{3}-\alpha_{1}\right)+\left(\left(\alpha_{1} \alpha_{4}-1\right)^{2}+2 \alpha_{2} \alpha_{3} \alpha_{4}\right)^{\frac{1}{2}}}{\alpha_{2} \alpha_{4}} \\
z^{*}=\frac{-1-\alpha_{4}\left(\alpha_{2} \alpha_{3}-\alpha_{1}\right)+\left(\left(\alpha_{1} \alpha_{4}-1\right)^{2}+2 \alpha_{2} \alpha_{3} \alpha_{4}\right)^{\frac{1}{2}}}{\alpha_{2} \alpha_{4}^{2}} .
\end{gathered}
$$

The scaling restriction in equation (2) is sufficient to imply that $\alpha_{1} \alpha_{4}<1, \alpha_{1}>\alpha_{2}$, and $\alpha_{3}<1$, so that $\lambda^{*}$ and $z^{*}$ are both positive. Also, from equations (11) and (13), we have that the loss in welfare due to the imperfect credibility is:

$$
\Delta W^{*}=\frac{\alpha_{0}}{2 E_{\mathrm{T}}} \lambda^{* 2}
$$

\footnotetext{
The integration performerl in equation (13) holds $n_{1}$ and $\alpha_{2}$ fixed (while in fact they may vary with $\lambda$ ), and therefore iclds anproximation to the current account. The most olvious simplification is in the domominator of ng, which may be withe the $\bar{F} D \Pi_{1} G_{10}$ is equal to the marginal propensity to save times the share of tariff writien explicitly as a function of $\lambda$. The $\Pi C_{1} \lambda{ }_{p}^{\tau_{p} C_{m}}$, which is small, and thus the Iruominator changes very little for small revenues in total second the integration in equation (13) arcominting for this effert. lut the aclilitional complication cloes not tariffs. We conld perform the int gration in ectro

(1983), Razin and Svrnsson (1982), and Edwards and van 10 These results are comparable to those of Svensson ant Razin (1983), Razim ant swrense the first. periorl current account Wijnbrgen (1983) who show, for the case of no wirterst.

deficit by lowering the real consumption rate of intrrest.
} 
Figure 2

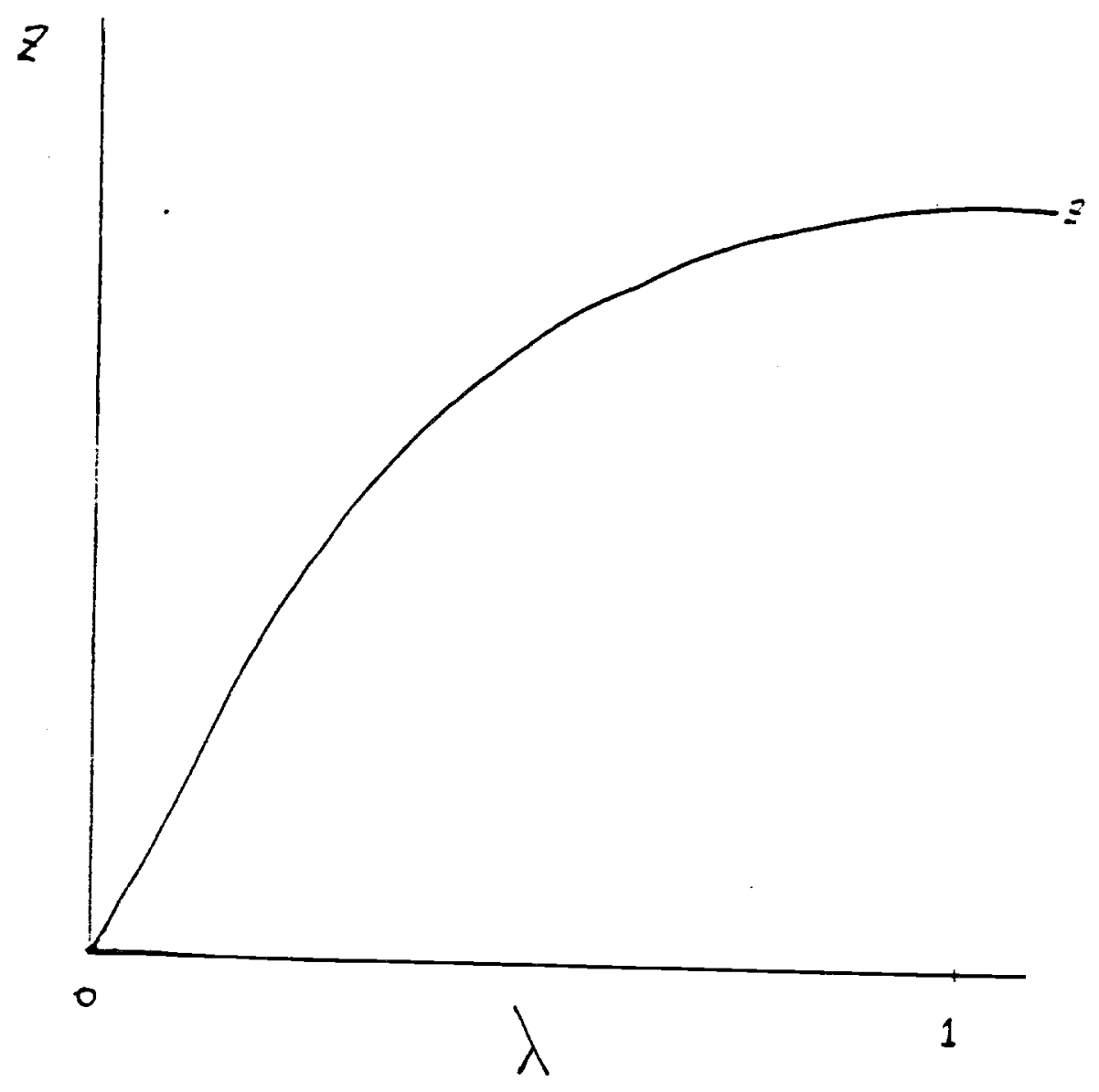


More intuition about the equilibrium can be gainer from a graph than from the algebraic solution. Figure 3 displays the current account and probability of collapse given in equations (13) and (5). As one might expect, greater intertemporal substitutability in consumption raises the equilibrium current account and probability of collapse. From equation (17), the lack of credibility imposes larger welfare losses when these intertemporal trausfers are more readily made. An increase in the world interest rate predictably reduces the current account deficit (since any given future surplus finances a smaller current deficit) and lowers $\lambda^{*}$ and $\Delta W^{*}$. Finally, increases in uncertainty about the future level of reserves (which raise the intercept and the slope of the $P$ curve in equation (14)) yield a higher probability of collapse, a greater current account deficit, and a lower level of welfare.

\subsection{A Second Best Argument for a Slower Rate of Trade Liberalization}

The model above can now be used to investigate the justification for positive first-period tariffs as a second-best tool for reducing the distortion introduced by a lack of perfect credibility. Such temporary tariffs may be added to the foregoing analysis by rewriting equations (8), (9), and (10) as follows:

$$
\begin{gathered}
E(\pi, D \Pi, W)=q\left(p_{m}, p_{x}\right)+D Q\left(P_{m}, P_{r}\right)+t+T \\
t=\tau_{1}\left(E_{1} \pi_{1}-q_{1}\right) \\
T=D \bar{\tau}\left(E_{2} \Pi_{1}-Q_{1}\right) \\
z=-\hat{q}+E_{1} \hat{\pi}
\end{gathered}
$$

where $t$ represents the lump sum transfer of revemus from the first-period tariff. Equation (20) is similar to (10), the hats indicate that the trade deficit is cvaluated at intemational prices instead of at distorted domestic prices. ${ }^{12}$ Differentiating equation (18) and using (19) we have the change in welfare resulting from a change in $\tau_{1}$ :

$$
\frac{E_{\mathrm{WV}} d W}{d \tau_{1}}=\frac{\tau_{p} D \cdot I \lambda+\tau_{1} c}{1-A-O}
$$

\footnotetext{
${ }^{12}$ This complicates matters since the usual cluality expressions must. le amencled. For exanple, on the protuction side first. period production in international prices is, $q=p_{m}^{*} q_{1}+q_{2}$. A change in the tariff alters domestic production decisions, but international prices remain fixed, $q_{1}=p_{m}^{*} q_{11}+q_{21}$. The domestic marginal rat.e of transformation satisfies $\left(p m+r_{1}\right) q_{11}+q_{21}=0$. The change in the value of iomestically produced goorls is therefore given $b_{y} q_{1}=-r_{1} q_{11}$.
} 
Figure 3

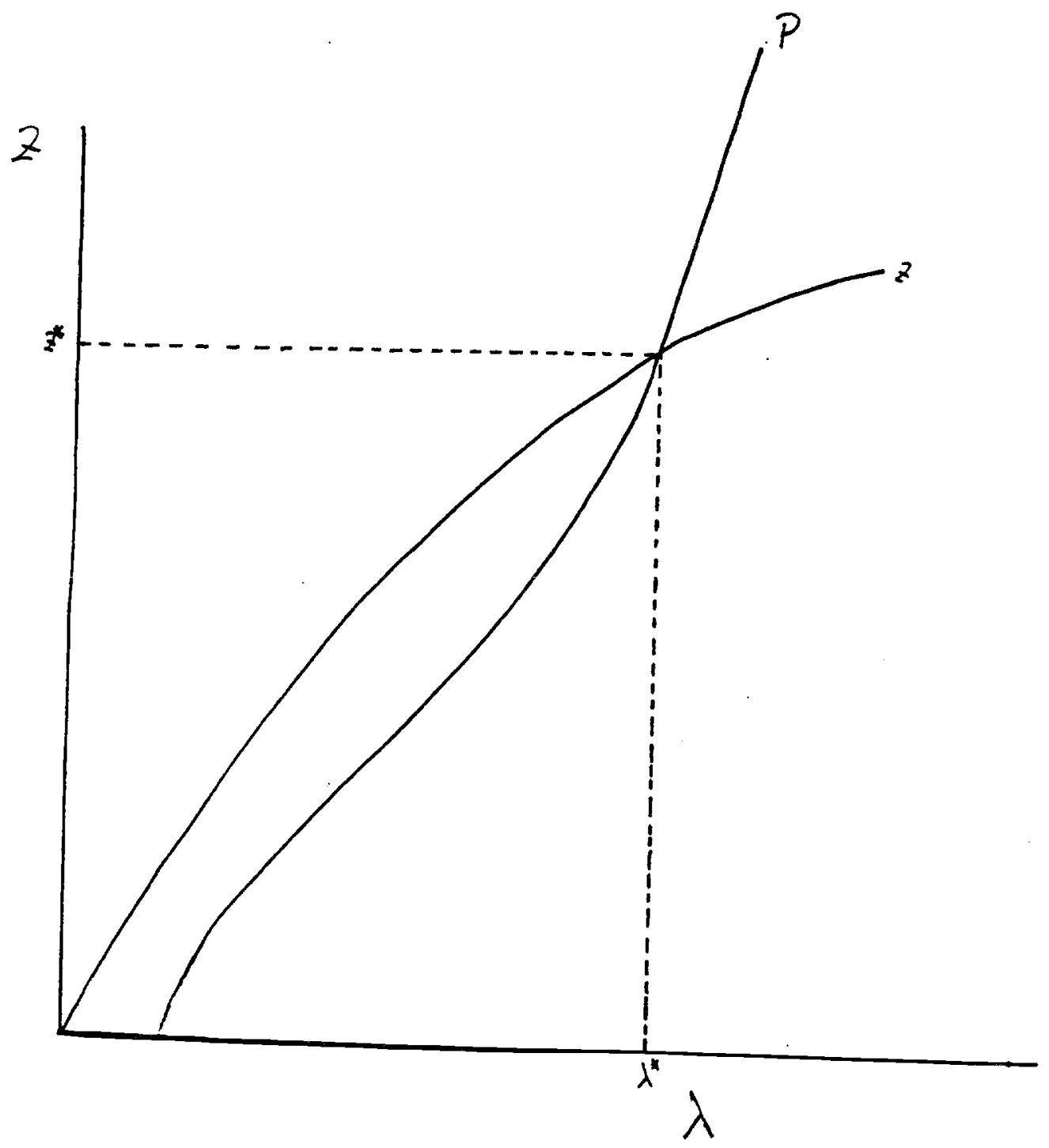


where

$$
\begin{gathered}
J=\Pi_{1} E_{21} \pi_{1}>0 \\
c=E_{1} \pi_{11}+\pi_{1} E_{11} \pi_{1}-q_{11}<0 \\
A=\bar{\tau} D \Pi_{1} C_{\mathrm{W}}>0 \\
O=\tau_{1} \pi_{1} c_{\mathrm{W}}>0 .
\end{gathered}
$$

The variable $J$ on the right-hand side of equation (21) captures the intertcmporal substitution effect. Although it arises from the introduction of a new first period tariff, it acts to raise welfare. Welfare improves because the real consumption rate of interest, $\frac{\pi}{\Pi D}$ (which is "too" low due to the anticipation of future tariffs), rises with $\tau_{1}$. Consumption is then shifted toward the future and the current account improves. Though the intertemporal distortion created by low credibility is mitigated by the imposition of $\tau_{1}$, there are obvious costs: a new distortion in the first period is introduced. The second term in equation (21) captures the reduction in welfare attributable to the intratemporal distortions produced by the first-period tariff. This term is proportional to $r_{1}$, so that, overall, a marginal first-period tariff tends unambiguously to improve welfare.

Ecpuation (21) also implies that there is a mique first-period tariff which maximizes welfare. Setting $d W=0$, we have:

$$
\tau_{1}^{*}(\lambda)=\alpha_{8} \lambda
$$

where

$$
\alpha_{8}=\frac{\tau_{p} D . J}{-c}>0
$$

Figure 4 shows a graph of $r_{1}^{*}(\lambda)$, the welfare maximizing temporary tariff, which is strictly positive for all non-zero $\lambda$. The reason $r_{1}^{*}$ is increasing in $\lambda$ is that the higher is the probability of failure, the greater is the distortion in the consumption rate of interest, and the more it is worth the cost of incurring a second distortion (in the form of a tariff in period onc) which will reduce the distortion in the real consumption rate of interest. For any given level of credibility, the govermment can raise welfare by liberalizing more slowly. 
Figure 4

The Optimal Tariff as a Function of the Probability of Reversal

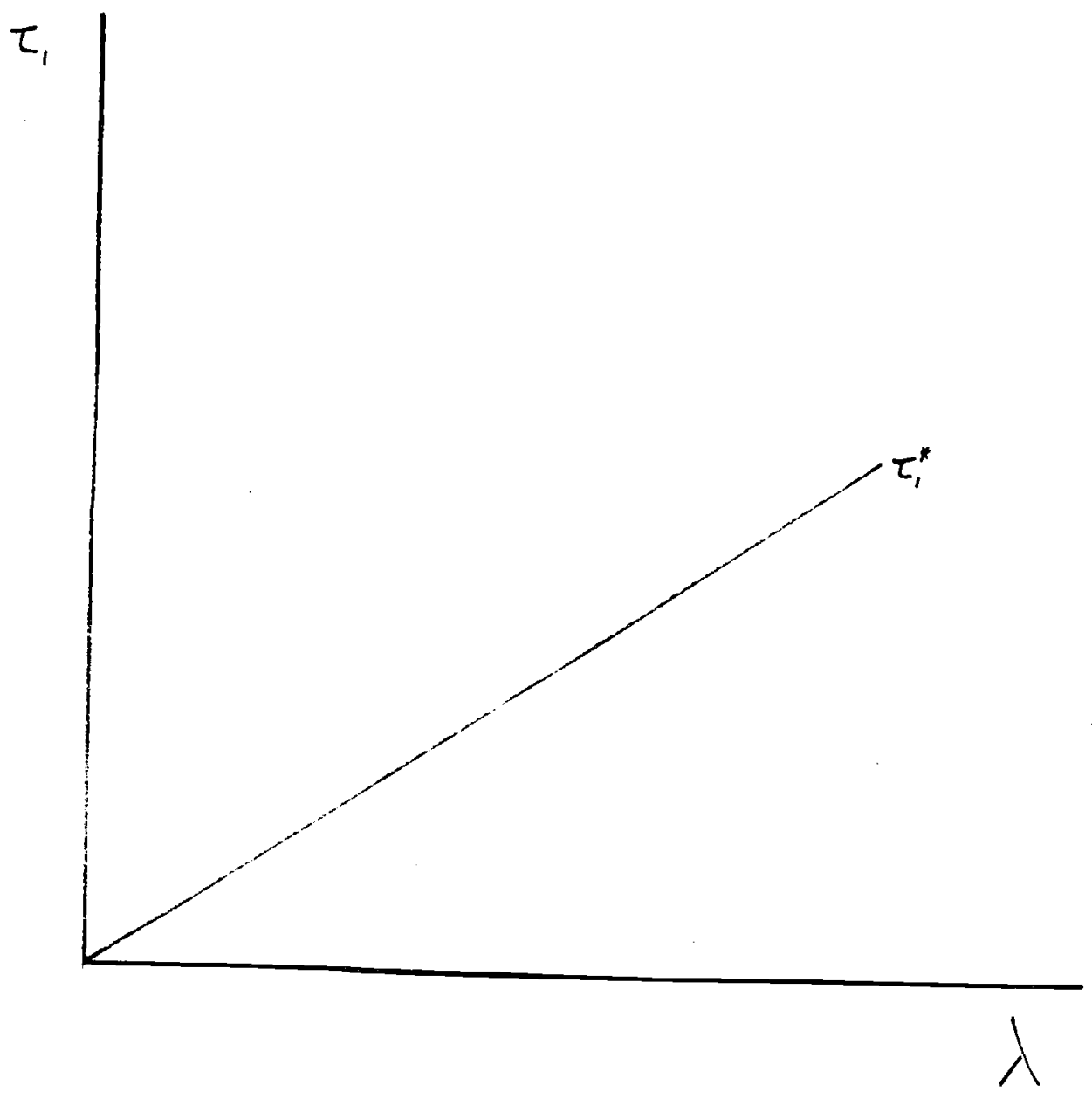


We now turn to the effects of tcmporary tariffs on the current arcount deficit. By differentiating equation (20) with respect to $\tau_{1}$ and using equation (22), we have:

$$
\frac{d z}{d \tau_{1}}=-\alpha_{6}-\alpha_{7} \tau_{1}
$$

where

$$
\begin{gathered}
\alpha_{6}=-\left(\pi-\tau_{1} \pi_{1}\right)\left(E_{11} \pi_{1}+\frac{\bar{\tau} D c_{W} \Pi_{1} E_{12} \pi_{1}}{1-\tau_{1} \pi_{1} c_{W}-\bar{\tau} \Pi_{1} C_{W}}\right)>0 \\
\alpha_{7}=-q_{11}+E_{1} \pi_{11}-\frac{c_{W}\left(\pi-\tau_{1} \pi_{1}\right)\left(E_{1} \pi_{11}+\pi_{1} E_{11} \pi_{1}-q_{11}\right)}{1-\tau_{1} \pi_{1} c_{W}-\bar{\tau} \Pi_{1} C_{W}} .
\end{gathered}
$$

The term $\alpha_{6}$ captures the intertemporal effects of the first-period tariff on expenditure and welfare. The tariff shifts spending toward the second period as the real consumption rate of interest rises; $\alpha_{0}$ will be positive as long as $\tau_{1}$ is not too large. ${ }^{13}$ Tariffs today will therefore offset the suboptimal reduction in the real consumption rate of interest cansed by positive expected tariffs tomorrow. The incentive to save increases and the current account improves. ${ }^{14}$

If we evaluate equation (25) at the optimal tariff as defined in equation (23), it can be shown that the current account improves for all $\tau_{1} \leq \tau_{1}^{*}$. From this fact, it follows that the level of the temporary tariff which maximizes the current account, call it $\check{r}_{1}$, is greater than the level of the optimal temporary tariff, $\tau_{1}^{*}$. This makes sense intuitively because for $\tau_{1} \geq \check{r}_{1}$, expenditure is transferred on the margin toward the first period. Welfare must already be declining.

The approximate improvement in the current accomt deficit from positive first period tariffs can be obtained by integrating equation (25) over $\tau_{1}$ :

$$
\Delta z\left(\tau_{1}\right)=-\alpha_{0} \tau_{1}-\frac{1}{2} \alpha_{7} \tau_{1}^{2}
$$

${ }^{12}$ More explicitly, $\alpha_{6}$ will be positive as long as:

$$
\pi c w \cdot \frac{r_{1} c m}{\pi \gamma}+\frac{\pi C m}{\Pi \Gamma}<1
$$

where $\frac{r_{1} c_{m}}{\pi \gamma}$ is the share of tariff reveme in first period spending and $\frac{F C_{m}}{75}$ is the expertecl share of tariff revenue in serond period-spending. A sufficient condition for this equation to hold is for tariff revemes to be less than 50 percent of nouninal

spending in each period.
14 The second parameter, $\alpha_{7}$, is less important for smaller $r_{1}$. This term reflects rhanges in current ronsumption and
phes in production due to the temporary tariff. The sign of $\alpha_{7}$ is ambiguous, lut will he positive as long as the intertemporal production due to the "lane" in comparion with the first periorl intratemporal sulıstitution efferts. To make this precise, $\alpha z$ will be positive if:

$$
-\pi c w \pi_{1} E_{11} \pi_{1}>(1-\pi c 11)\left(q_{11}-E_{1} \pi_{11}\right)
$$


It is convenient to define a function which allows us to sce low changes in first-period tariffs affect the current account as $\lambda$ varics:

$$
\begin{gathered}
\mathbf{z}\left(\tau_{1}, \lambda\right)=z(\lambda)+\Delta z\left(\tau_{1}\right) \\
=\alpha_{1} \lambda-\frac{1}{2} \alpha_{2} \lambda^{2}-\alpha_{6} \tau_{1}-\frac{1}{2} \alpha_{7} \tau_{1}^{2} .
\end{gathered}
$$

Figure 5 demonstrates the effect on the current account of first-period tariffs (equation (27')). An increase in the probability that the liberalization program will collapse, from $\lambda_{0}$ to $\lambda_{1}$, worsens the tradeoff between current account deficits and first-period tariffs, shifting the $\mathrm{z}$ curve out and to the right. ${ }^{15}$ Figure 6 shows how the tradeoff between current account deficits and a lack of perfect credibility improves with the addition of small temporary tariffs. In $z-, \lambda$-spare, the $\mathbf{z}$ curve shifts down when first-period tariffs are imposed.

We now have three equations in three unknowns: the current acconnt deficit, $z$, the probability of collapse of the liberalization program, $\lambda$, and the optimal temporary tariff, $r_{1}^{*}$ :

$$
\begin{gathered}
\mathbf{z}\left(\tau_{1}, \lambda\right)=\alpha_{1} \lambda-\frac{1}{2} \alpha_{2} \lambda^{2}-\alpha_{6} \tau_{1}-\frac{1}{2} \alpha_{7} \tau_{1}^{2} \\
\tau_{1}^{*}(\lambda)=\alpha_{8} \lambda \\
\lambda=P\left(R_{\text {min }}, \sigma_{\mu 1}^{2}, z\right)=\alpha_{3}+\alpha_{4} z .
\end{gathered}
$$

Figure 7 characterizes the welfare maximizing solution. In the upper right-hand quadrant are the $P$ (equation (30)) and $\mathbf{z}$ (equation (28)) curves. They intersect initially at the instantaneous liberalization equilibriun, point $A$. In the lower-right quadrant is a 45 degree line, mapping $\lambda$ into itself. The third quadrant contains the $\tau_{1}^{*}$ curve (equation (29)), which translates a given level of credibility into an implied optimal first-period tariff. Finally, in the upper left is the $z$ curve in $z_{-}, \tau_{1}$-space (equation (28)), which reports the current account deficit associated with different first-period tariffs, given values of $\lambda$ generated by intersections of the $P$ and $z$ curves in the first quadrant.

\footnotetext{
${ }^{15}$ For simplicity this curve is drawn as downwaril sloping. At levels of $r_{1}$ aloow the nptimal tariff, howerver, a becomes
negative and the $\mathrm{z}$ curve, drawn in $z, \tau_{1}$ space, begins to slope npwarcl.
} 


\section{Figure 5}

The Change in the Current Account from a Shift in the Probability of Reversal as a Function of First-Period Tariffs

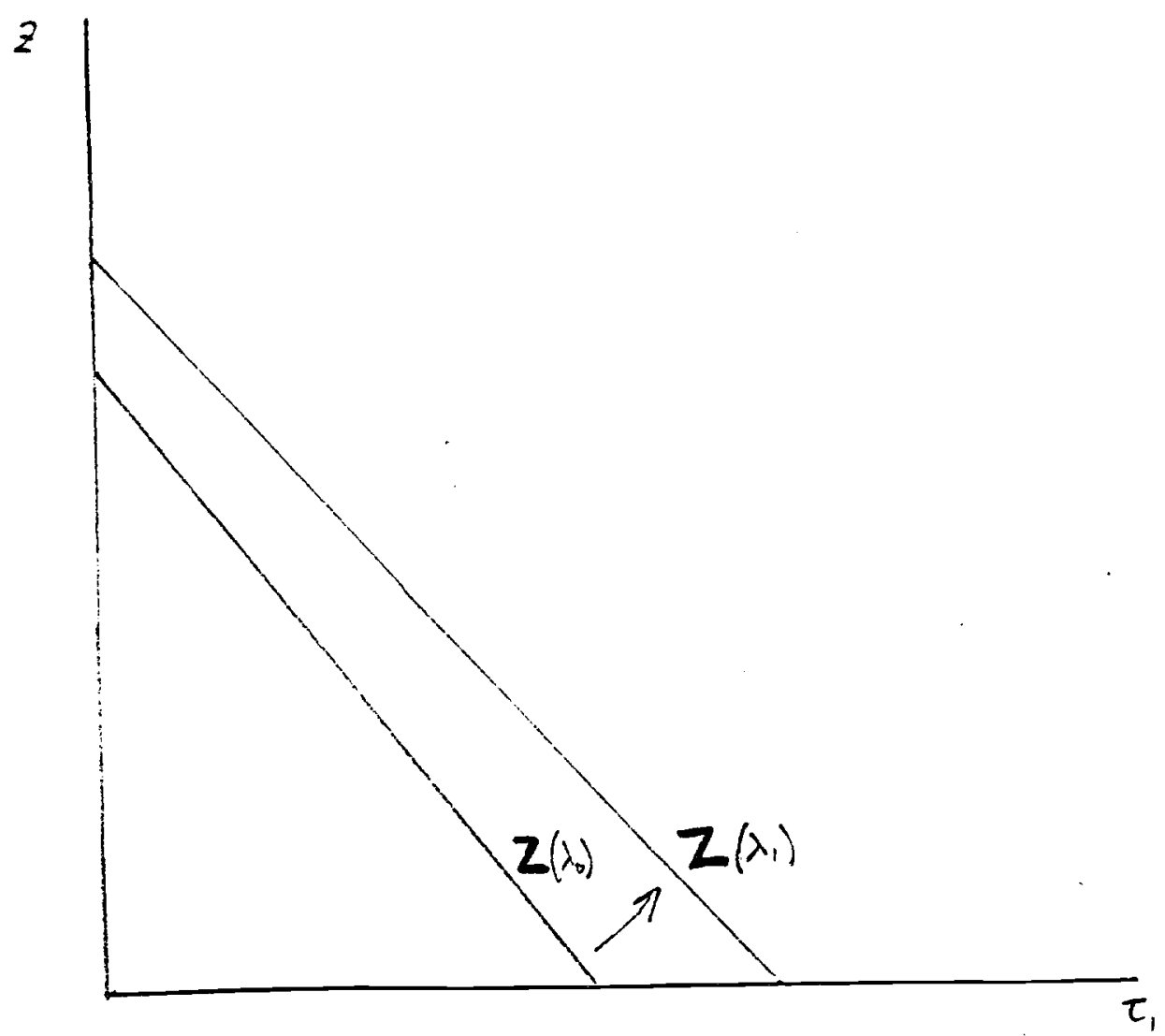


The Change in the Current Account from a Shift in First-Period Tariffs as a Function of the Probability of Reversal

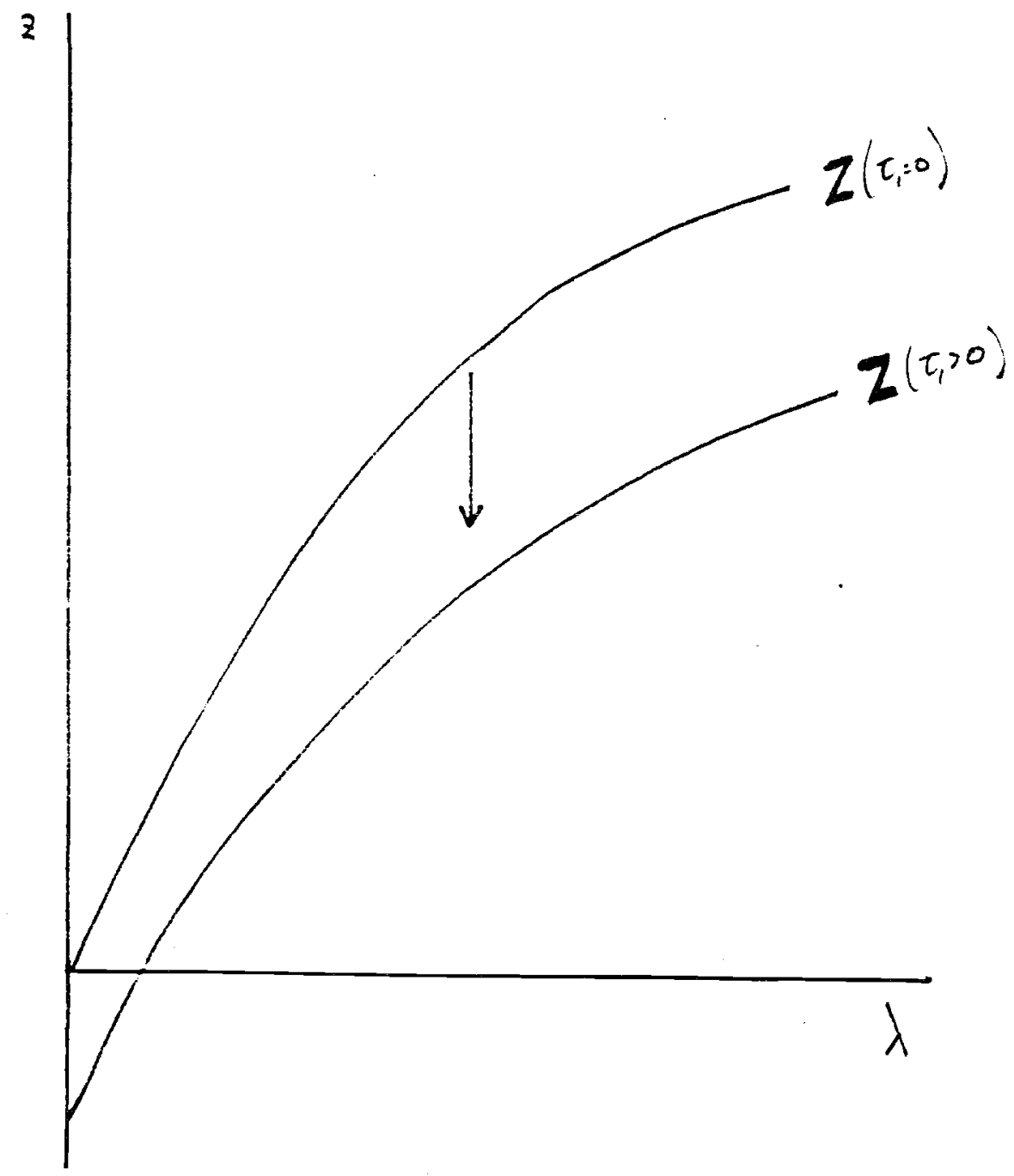


Figure 7

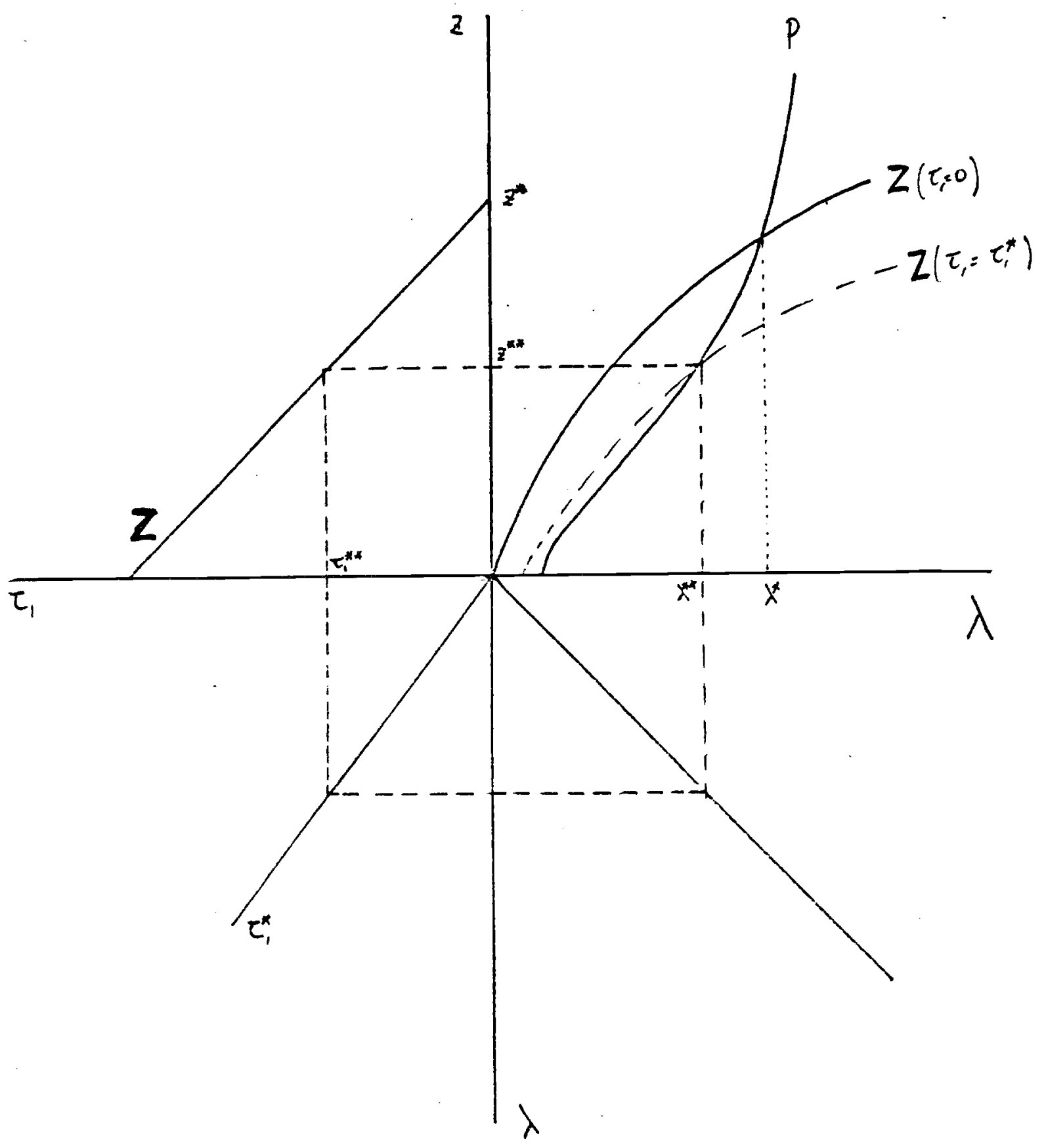


Consider now what happens if the liberalization proceeds more slowly. Positive tariffs in period one shift the $z$ curve in the first quadrant down. This defines a new intersection of the $P$ and $z$ curves at a lower current account deficit and lower $\lambda$, marked by point B. Moving in a clockwise direction into the third quadrant, the $\tau_{1}^{*}$ curve gives the optimal temporary tariff. In the upper left quadrant, the value of the optimal tariff is translated into a corresponding current account deficit. If the deficit is the same as that generated by the intersection of the $z$ and $P$ curves, we have found the fixed point B. If it is not, we try a higher (or lower) $\tau_{1}$, shifting the $z$ curve further down (or up). The fixed-point values, $\tau_{1}^{* *}, z^{* *}, \lambda^{* *}$, give the optimal spced of liberalization, the optimal current account deficit, and the resulting degree of credibility, given the underlying parameters $R$, $\sigma_{\mu}^{2}, R_{m i n} .^{16}$ It is straightforward to show that $0<z^{* *}<z^{*}, 0<\lambda^{* *}<\lambda^{*}$, and $0<\tau_{1}^{* *}$. A liberalization program which removes tariffs directly and has less than perfect credibility can be improved upon by slowing the speed at which tariffs are reduced.

It is also possible to do some comparative statics with this model. An increase in the level of reserves, will raise $R_{\min }$ and lower $z^{* *}, \lambda^{* *}, \tau_{1}^{* *}$ as shown in Figure 8 . Here the $P$ curve shifts left (its slope decreases as well) and the $\mathrm{z}$ curve in $z-, \tau_{1}$-space shifts down, since the improvement in credibility implies that at any given level of $\tau_{1}$, the current acconnt deficit will be lower. The initial optimum is given by $\lambda^{* *}, \tau_{1}^{* *}$ and $z^{* *}$ and the new optimum by $\lambda^{* * *}, r_{1}^{* * *}$ and $z^{* * *}$. Greater international liquidity, evidenced by a lower level of $R_{m i m}$, will have the same qualitative effect on the equilibrium: the P curve shifts to the left as the program's susceptibility to trade balance shocks improves. The higher the level of reserves, and the casier it is to negotiate additional intemational lending, the greater the optimal speed of libcralization. An increase in the variance of unexpected shocks to reserves, $\sigma_{\mu}^{2}$, shifts the $\mathrm{P}$ curve in a different manner, slown in Figure 9 . The result is that $z^{* *}, \lambda^{* *}, \tau_{1}^{* *}$ all increase: the optimal rate liberalization is even slower.

It is worth stressing that on average more resources are devoted to exports in period two when the liberalization proceeds gradually than when the liberalization is immediate. In terms of Figure 1, temporary tariffs cause a smaller decrease in the expected relative price of exports and wage/rental ratio, so that the shift in resources toward imports is less pronounced. This reallocation of resources is important since one motivation for undertaking a liberalization program in the first

\footnotetext{
${ }^{16}$ Because the algebraic solutions for $\lambda^{* *}, z^{* *}$, and $r_{i}^{* *}$ are cumbersome and yield no alditional insights, they are omitted
here.
} 
Figure 8

An Increase in Reserves Shifts the PP Curve Left

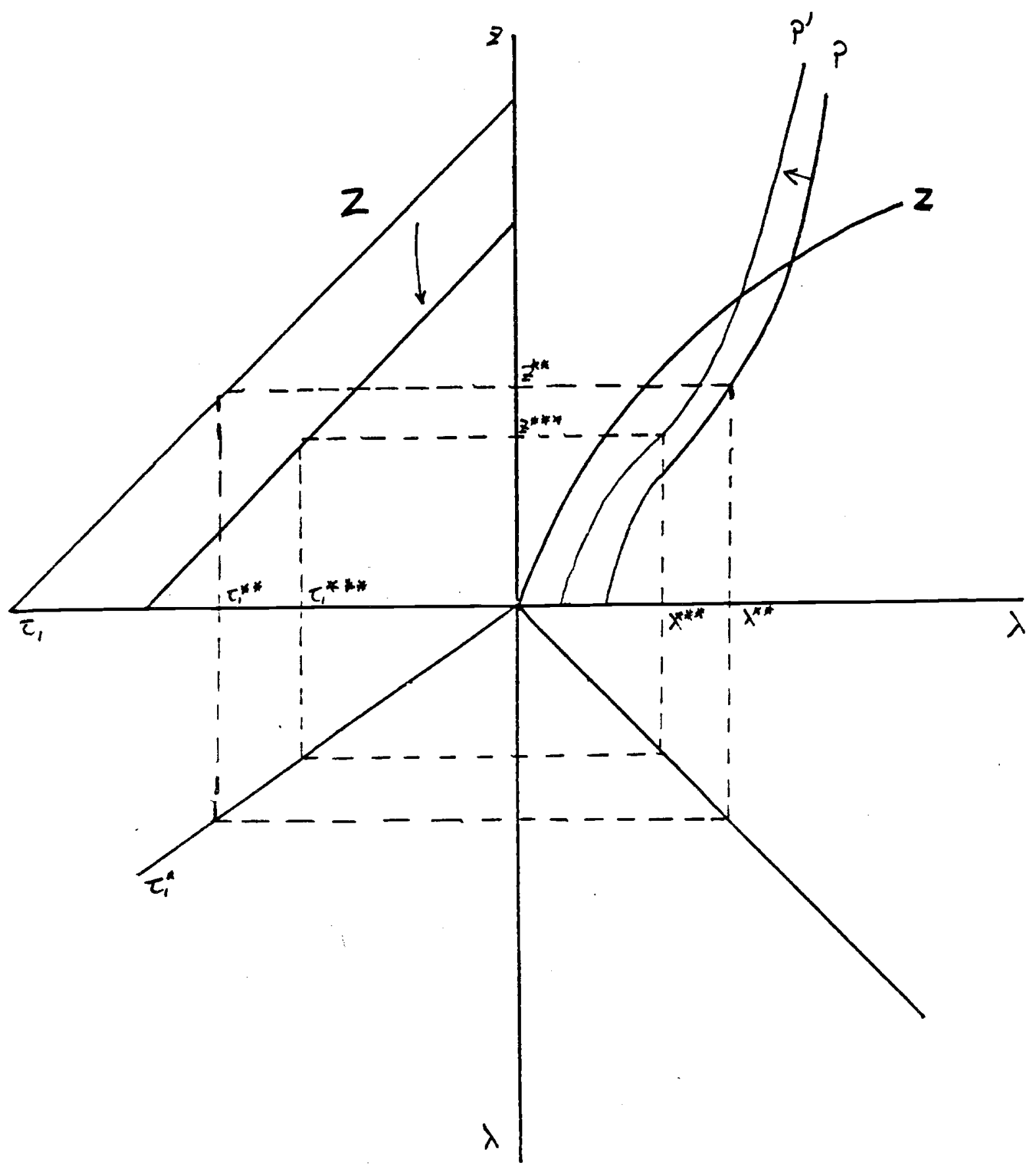


Figure 9

An Increase in Uncertainty in International Markets

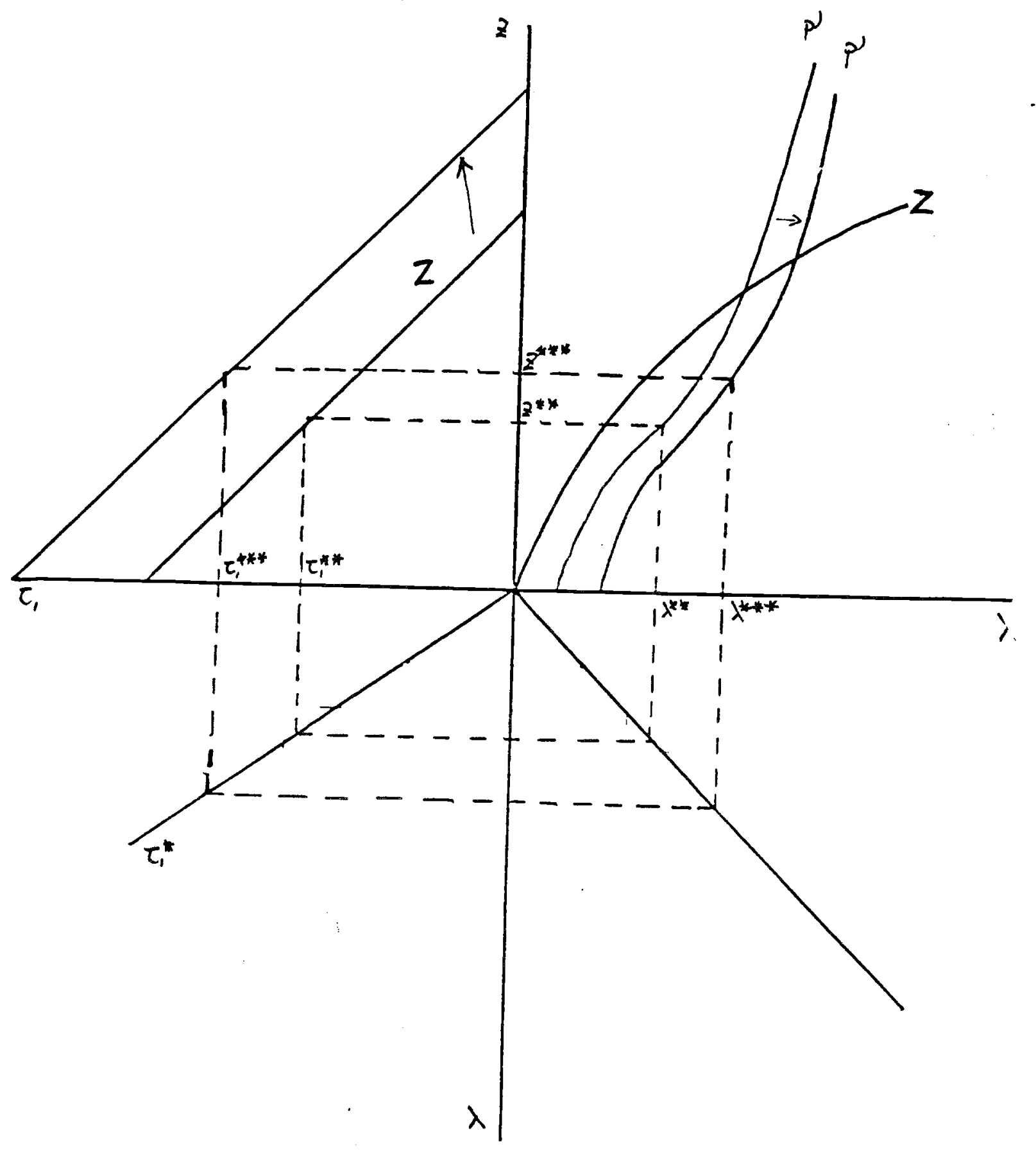


place is to boost the allocation of resources in export sectors.

\section{Expected Collapse of a Liberalization Program when Reserves are Rationed}

The previous section explored the kind of difficultics which confront a less than fully credible removal of tariffs when domestic reserves are made available to finance the private sector's current accourt deficit. Frequently, however, reserves are rationed by the govermment, so that additional borrowing by the private sector is not possible. In this section we look at the effects of an incredible liberalization when the current account is fixed by the authoritic's. The private sector's excess demand for loans in the initial period is vitiated in the model below by a rise in the domestic interest rate, which compensates individuals who would otherwise want to consume more in the first period. The budget constraint now becomes

$$
\begin{gathered}
E(\pi, D \Pi, W)=q+D Q+T+\left(D^{*}-D\right)\left(Q-E_{2} \Pi\right) \\
T=D \bar{\tau}\left(E_{2} \Pi_{1}-Q_{1}\right),
\end{gathered}
$$

where $D^{*}=\frac{1}{1+i^{*}}$ and $i^{*}$ is the nominal world rate of interest. In equation (31), we treat the higher domestic interest rate as a tax on first period borrowing. The term $\left(D^{*}-D\right)\left(Q-E_{2} I \mathrm{I}\right)$ represents the redistribution of the revenues from the tax. We assume that these taxes are calculated in terms of real goods, evaluated at period-two domestic prices. The current account constraint is given by

$$
\bar{Z}=D^{*}\left(\hat{Q}-E_{2} \hat{\Pi}\right)
$$

where the hats indicate that the current acconnt is fixed in terms of international currency. To see how the domestic discount rate varies in response to positive expected future tariffs we differentiate equations (31) and (32) using (33):

$$
\begin{gathered}
\left(\begin{array}{cc}
1+\left(D^{*}-D\right) N-D a \lambda & \left(D^{*}-D\right) F-\bar{\tau}(D B+V) \\
N-a \lambda & F-\bar{\tau} B
\end{array}\right)\left(\begin{array}{c}
E_{\mathrm{W}} d W \\
d D
\end{array}\right) \\
=\left(\begin{array}{c}
\left(-\left(D^{*}-D\right)(V+G)+\bar{\tau} D C\right) \tau_{p} \\
(\bar{\tau} C-G) \tau_{p}
\end{array}\right) d \lambda
\end{gathered}
$$

where

$$
a=\tau_{p} \Pi_{1} C_{\pi r}>0
$$




$$
\begin{gathered}
B=\Pi_{1} E_{22} \Pi<0 \\
C=\Pi_{1} E_{22} \Pi_{1} D+E_{2} \Pi_{11}-Q_{11}<0 \\
F=\Pi E_{22} \Pi<0 \\
G=\Pi E_{22} \Pi_{1} D<0 \\
N=\Pi C_{\pi r}>0 \\
V=E_{2} \Pi_{1}-Q_{1}>0
\end{gathered}
$$

Applying Cramer's rule to equation (34), some algebra yiclds the solutions:

$$
\begin{gathered}
E_{\mathrm{W}} d W=\frac{1}{\Delta}\left((F-\bar{\tau} B)\left(D-D^{*}\right) V+\bar{\tau}\left(D^{*}-2 D\right)(G B-F C)+\bar{\tau} V(\bar{\tau} C-G)\right) d \lambda \\
d D=\frac{1}{\Delta}\left(\bar{\tau} C\left(1-\left(2 D-D^{*}\right) N\right)-G(1-D a \lambda)-\left(D^{*}-D\right) a \lambda G-(a \lambda-N)\left(D^{*}-D\right) V\right) d \lambda .
\end{gathered}
$$

The determinant of the matrix on the left-hand side of (34), $\Delta$, is negative as shown in Appendix 2. Appendix 3 gives gives explicit limits on the size of $\tau_{p}$ to guarantee that $\frac{E_{W} d W}{d \lambda}<0$ in equation (36). It is easy to be convinced on an intuitive level that welfare should fall. As individuals' expectations of future tariffs increase, the expected distortion rises and so welfarc is reduced. This seemingly obvious result is complicated in the above equation because the domestic interest rate is free to fluctuate in response to pressure on the current account, and will presumably do so in a way that tends to raise welfare above what it would have been if it were fixed.

Equation (37) gives the response of the interest rate to changes in expected future tariffs. The lack of perfect credibility lowers the consumption rate of interest and encourages consumption, causing the current account constraint to bind nore severely. Consequently, interest rates must rise in order to compensate individuals for the immediate consumption they otherwise would desire. ${ }^{17}$

Figure 10 demonstrates this mechanism using the $P$ and $z$ curves from the previous section. Now, however the ex ante current account is pegged at $\bar{Z}$. At point $\mathrm{B}$ the current account constraint 17 If the expected tariff becomes too large, however, then once again the negative welfare effects swamp the results: desired
first-period consumption falls, the current account constraint becomes tese limeline aur the ing therefore negative and interest rates rise with $\lambda$ if

$$
\tau_{p}<\frac{G(1-D a)+\left(D^{*}-D\right) a G+(a-N)\left(D^{*}-D\right) v}{C\left(1-\left(2 D-D^{*}\right) N\right)} .
$$


Figure 10

Domestic Interest Rates and the Closed Capital Account ?

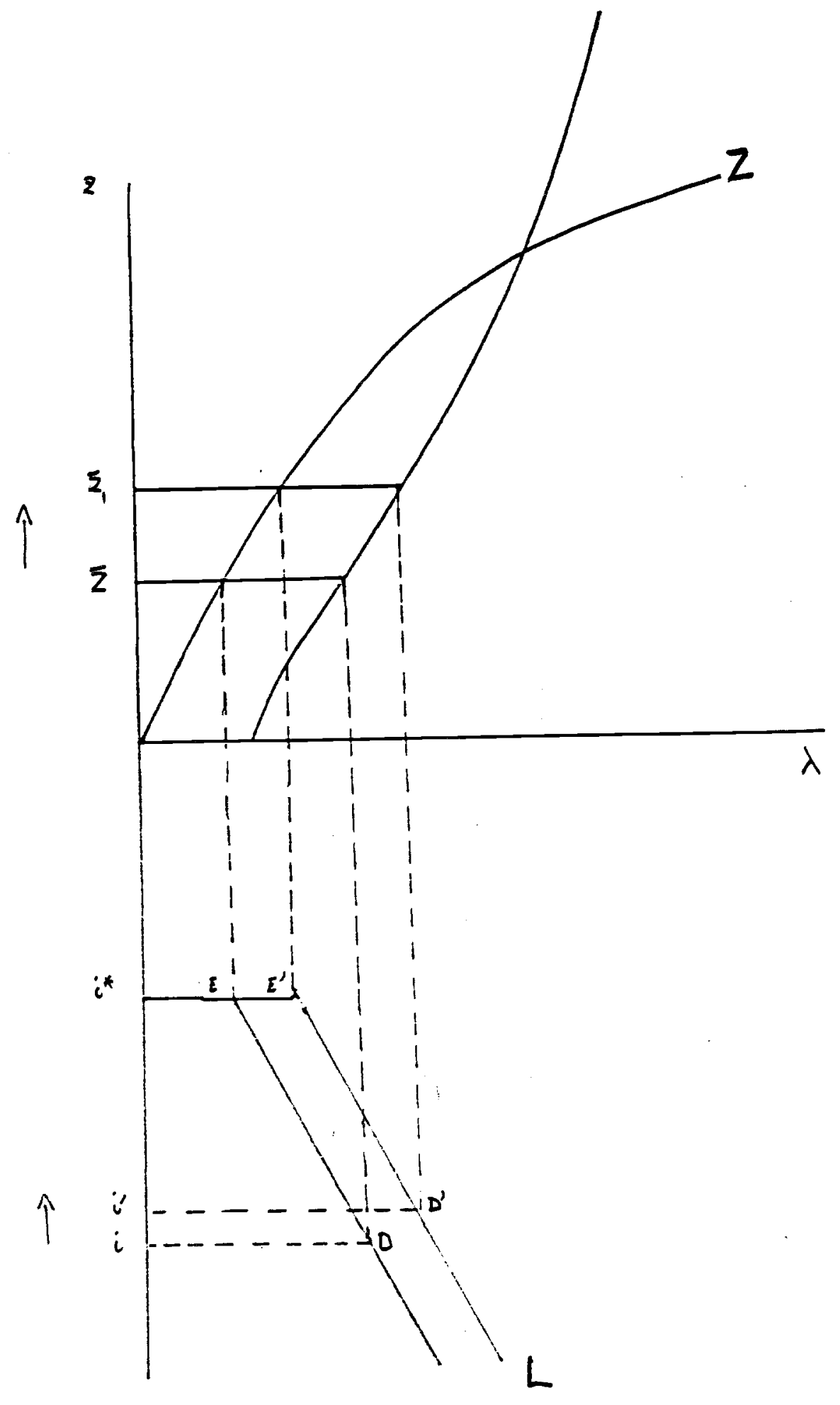


is just binding, so that $D=D^{*}$ and, from equation $(11), \bar{\lambda} \approx \frac{\bar{z}}{\alpha_{1}}$. The equilibrium, $\lambda=\lambda^{*}$ (point C), has associated with it a domestic interest rate which excecds the world rate (point D). Although it is not tractable analytically, it is in principle possible to integrate $(37)$ from $\bar{\lambda} \approx \frac{\bar{z}}{\alpha_{1}}$ to $\lambda^{*}$ to get the domestic interest differential, $D^{*}-D$ :

$$
L(\bar{Z}, \lambda)=\int_{\frac{Z}{n_{1}}}^{\lambda^{*}} d D(\lambda) d \lambda .
$$

From equation $(37), \frac{\partial L(\bar{Z}, \lambda)}{\partial \bar{Z}}<0$ and $\frac{\partial L(\bar{Z}, \lambda)}{\partial \lambda}>0$. Figure 10 also shows the effect on the domestic interest rate of a change in the borrowing constraint from $\bar{Z}$ to $\bar{Z}^{\prime}$. When the current account fixed at $\bar{Z}^{\prime}$, interest rates begin to rise at point E' instead of point E. At a given level of credibility, the equilibrium domestic interest rate is falls when the capital constraint is loosened: point $D^{\prime}$ 'implies a lower interest rate than D. Welfare improves unambiguously.

\subsection{A Slower Rate of Liberalization when Reserves are Rationed}

Now we can proceed to analyze the optimal speed of liberalization when reserves are rationed. The budget constraint is similar to equation (31):

$$
\begin{gathered}
E(\pi, D \Pi, W)=q+D Q+t+T+\left(D^{*}-D\right)\left(Q-E_{2} \Pi\right) \\
T=D \tilde{\tau}\left(E_{2} \Pi_{1}-Q_{1}\right) \\
t=\tau_{1}\left(E_{1} \pi_{1}-q_{1}\right),
\end{gathered}
$$

with $t$ representiug first-period tariff revenues. The current account is given by equation (33):

$$
\bar{Z}=D^{*}\left(\hat{Q}-E_{2} \hat{\Pi}\right)
$$

Taking the derivative of equations (39) and (42), and using cepuations (40) and (41) we have:

$$
\begin{gathered}
\left(\begin{array}{cc}
1+\left(D^{*}-D\right) N-D a \lambda-O & \left(D^{*}-D\right) F-\bar{\tau}(V+D B)-\tau_{1} H \\
N-a \lambda & F-\bar{\tau} B
\end{array}\right)\left(\begin{array}{c}
E_{\mathrm{WV}} d W \\
d D
\end{array}\right) \\
=\left(\begin{array}{c}
D J \bar{\tau}+c \tau_{1}-\left(D^{*}-D\right) H \\
J_{\bar{\tau}}-H
\end{array}\right) d \tau_{1},
\end{gathered}
$$

where 


$$
\begin{gathered}
a=\tau_{p} \Pi_{1} C_{W}>0 \\
O=\pi_{1} \pi_{1} c_{W}>0 \\
B=\Pi_{1} E_{22} \Pi<0 \\
c=E_{1} \pi_{11}+\pi_{1} E_{11} \pi_{1}-q_{11}<0 \\
C=\Pi_{1} E_{22} \Pi_{1} D+E_{2} \Pi_{11}-Q_{11}<0 \\
F=\Pi E_{22} \Pi<0 \\
H=\pi_{1} E_{12} \Pi>0 \\
N=\Pi C_{W}>0 \\
J=\Pi_{1} E_{21} \pi_{1}>0 \\
V=E_{2} \Pi_{1}-Q_{1}>0 .
\end{gathered}
$$

Equation (43) yields:

$$
\begin{aligned}
\frac{E_{W} d W}{d \tau_{1}} & =\frac{1}{\Delta} \tau_{1}(c(F-\bar{\tau} B)+H(. J \bar{\tau}-H))+\bar{\tau} V(J \bar{\tau}-H) \\
\frac{d D}{d \tau_{1}} & =\frac{1}{\Delta}\left(J \bar{\tau}-H+\tau_{1}(c(a-N)-O(J \bar{\tau}-H))\right) .
\end{aligned}
$$

Setting (45) equal to zero and solving for the optimal tariff in period one, we obtain:

$$
\tau_{1}^{*}(\lambda)=\frac{\alpha_{9}}{\alpha_{10}} \lambda>0
$$

where

$$
\begin{gathered}
\alpha_{9}=-\tau_{p} V(J \bar{\tau}-H)>0 \\
\alpha_{10}=(c(F-\bar{\tau} B)+H(J \bar{\tau}-H))>0 .
\end{gathered}
$$

The optimal tariff is once again increasing and approximately linear in $\lambda$ : when credibility is low, more can be gained from instituting larger first-period tariffs. ${ }^{18}$

\footnotetext{
${ }^{18}$ In equation (48), $\alpha_{1} 0$ appears to have an anbiguous sign. A simple continuity argument, serves to show that it must be positive. The fact that $a l_{9}$, is greater than zero implies that the change in welfare from a first periol tariff, evaluated when $\tau_{1}$ is zero, is unambiguously positive. As long as the first derivative of wrifare is continums, small increases in the level of $\tau_{1}$ will raise the level of welfare. Thus, at least for small first periocl tariffs, $\alpha_{1} 0$ is positive.
} 
Next we consider the behavior of interest rates when tariffs are imposed in the initial period. From equation (46) we have:

$$
\frac{d D}{d \tau_{1}}=\alpha_{11}-\alpha_{12} \tau_{1}
$$

where

$$
\begin{gathered}
\alpha_{11}=\frac{1}{\Delta}\left(\bar{r} \Pi_{1}-\Pi\right) \pi_{1} E_{21}>0 \\
\alpha_{12}=\frac{1}{\Delta}\left(\bar{r} \Pi_{1}-\Pi\right)\left(\pi_{1} E_{21} \pi_{1} c_{\mathrm{W}}-c C_{\mathrm{W}}\right)>0 .
\end{gathered}
$$

Equation (50) implies that interest rates will fall as a result of higher temporary tariffs provided that $\tau_{1}<\frac{\alpha_{11}}{\alpha_{12}}$. A simple intuitive argument serves to demonstrate that the domestic interest rate remains above the world rate at the optimal tariff, $\tau_{1}^{* *}$. The only benefit to raising $\tau_{1}$ comes from a decline in the interest rate ( $\lambda$ is fixed). The cost of such a policy is the temporary distortion that tariffs induce. At the point where $\tau_{1}=\frac{\alpha_{11}}{\alpha_{12}}$, the benefits of raising tariffs further are zero, but the costs of the added distortion are positive. It follows that welfare can be at a maximum only when the benefits are still positive, i.e. that $\tau_{1}<\frac{\alpha_{11}}{\alpha_{12}}$.

From equation (50) we can integrate over $\tau_{1}$ to obtain:

$$
\mathbf{L}\left(\bar{Z}, \lambda, \tau_{1}\right)=L(\bar{Z}, \lambda)-\alpha_{11} \tau_{1}+\frac{1}{2} \alpha_{12} \tau_{1}^{2}
$$

which gives the level of the interest rate for given values of $\lambda, \tau_{1}$, and $\bar{Z}$.

We can now solve for the optimal first-period tariff and the equilibrium level of credibility and domestic interest rate. There are three equations and three unknowns:

$$
\begin{gathered}
\lambda=P\left(R_{\min }, \sigma_{p}^{2}, \bar{Z}\right)=\alpha_{3}+\alpha_{4} \bar{Z} \\
\tau_{1}^{*}(\lambda)=\frac{\alpha_{9}}{\alpha_{10}} \lambda \\
\mathbf{L}\left(\bar{Z}, \lambda, \tau_{1}\right)=D D(\bar{Z}, \lambda)-\alpha_{11} \tau_{1}+\alpha_{12} \tau_{1}^{2} .
\end{gathered}
$$

The solution is displayed in Figure 11. Note that $\lambda^{*}$ is determined by $\bar{Z}$ and equation (53), so that the above system is recursive. Given $\lambda^{*}$, equation (54) yields the optimal tariff, $\tau_{1}^{* *}$. Equation 


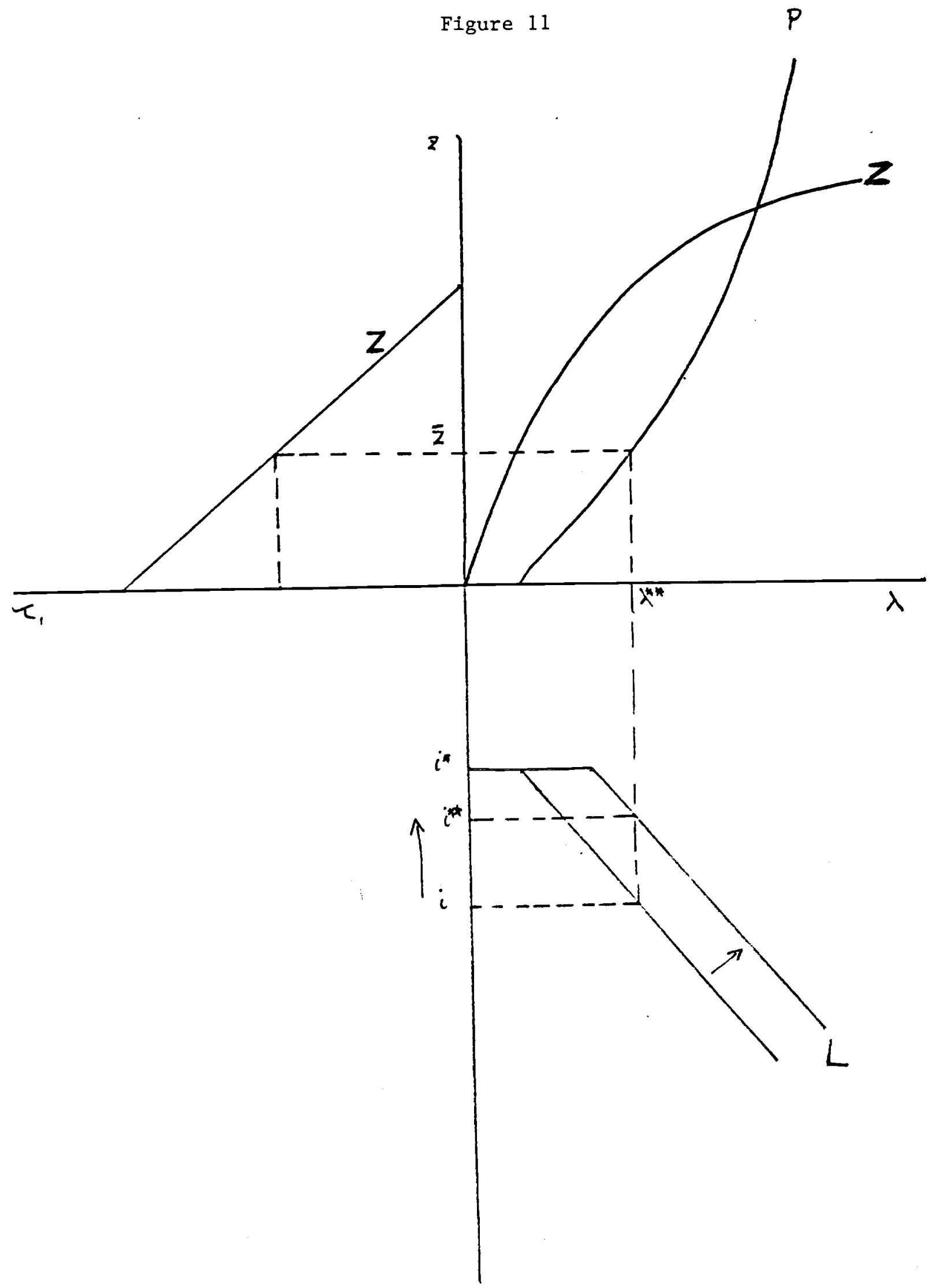


(55) then gives the equilibrium domestic interest rate, $i^{* *}$. When the current account is fixed by government fiat and domestic interest rates are consecquently driven above world rates, gradual liberalization appears to be the optimal policy in the face of imperfect credibility.

In many cases, a reduction in the speed of libcralization will case pressure on the current account constraint, and in some cases the constraint will no longer bind. If this occurs, we are in the situation described in section 2, and the tendency for temporary tariffs to improve welfare and the efficiency of resource allocation is strengthened over and above the arguments presented in this section, since first-period tariffs purchase both reductions in the domestic interest rate as well as improvements in credibility. 


\section{Conclusions}

When the private sector can obtain hard currency to finance its desired current account deficit, an imperfectly credible and immediate attempt to liberalize trade results in a positive current account deficit and rational positive probability that the liberalization will ultimately fail. Positive expected future tariffs tend to increase future production opportunities in the import sector relative to the export sector. The imperfect credibility built into our model thus tends to undermine one important notivation for removing tariffs to begin with: to shift productive resources out of the protected import sector and into the efficient export sector.

A slower rate of trade liberalization can increase welfare over the equilibrium in (1), as long as the temporary first-period tariffs are not too large. This cquilibrium dominates that of the instantaneous liberalization in that the current account deficit is smaller, $z^{* *}<z^{*}$, the probability of the program's failure is lower, $\lambda^{* *}<\lambda^{*}$, and welfare is greater. There is a unique (positive) first-period tariff which maximizes intertemporal welfare. Second period production in the import sector is on average lower with such temporary tariffs. Thus, a more gradual speed of liberalization may actually help encourage a shift of resources from the inport sector into the export sector.

For the case in which the current account is constrained by rationing of reserves, imperfect credibility translates into domestic interest rates that are above those in the rest of the world. We show that in such circumstances, an immediate and complete tariff reduction is inferior to a more gradual approach. When such temporary tariffs are imposed, the domestic interest rate is lower than it would be under instantaneous liberalization (but it remains above the world rate). The behavior of the interest rate in this instance indicates that it is particularly problematic for countries with foreign exchange constraints to liberalize successfully. When high interest rates force down the capital stock in the export sector, it becomes all the more difficult to obtain fresh loans. Thus, in the common case in which a current account constraint is a consequence of a low level of reserves and too little international licpuidity, an incredible libcralization program may push further into the future the day when voluntary lending and borrowing can be resumed. 


\section{Appendix 1}

In this appendix we investigate further the treatment of uncertainty used in the text. Our basic problem is to determine the comparative statics of the model discussed in section two when $\lambda$, the probability that the liberalization program will fail, changes. Because the consumption and production problems for our small country are formally identical, we need to look at a single example only. Here we investigate the maximization of period two subutility:

$$
\max \left\{\Gamma\left(C_{m}, C_{r}\right): \tilde{P}_{m} C_{m}+C_{r}=y\right\}
$$

where $y$ is second-period real income, which is taken as fixed by the consumer. By substituting in the budget constraint, we can rewrite $(A 1.1)$ as

$$
\max _{C_{m}}\left\{\Gamma\left(C_{m}, y-\tilde{P}_{m} C_{m}\right)\right\}
$$

The first order condition is:

$$
E\left[\Gamma_{1}\right]=E\left[\Gamma_{2} \tilde{\Gamma}_{m}\right]
$$

where $\vec{P}_{m}=E\left[\tilde{P}_{m}\right]=p_{m}^{*}+\lambda \tau_{p}$. To find expected utility, we take Taylor series expansions around $\tilde{P}_{m}=\bar{P}_{n}$ :

$$
E\left[\Gamma_{1}\right] \approx E\left[\bar{\Gamma}_{1}-\bar{\Gamma}_{22} C_{m}\left(\tilde{P}_{m}-\bar{P}_{m}\right)+\frac{1}{2} \bar{\Gamma}_{122}\left(\tilde{\Gamma}_{m}-\bar{P}_{m}\right)^{2} C_{m}^{2}\right]
$$

$$
E\left[\tilde{P}_{m} \Gamma_{2}\right] \approx E\left[\bar{P}_{m} \bar{\Gamma}_{2}+\left(-\bar{P}_{m} \bar{\Gamma}_{22} C_{m}+\bar{\Gamma}_{2}\right)\left(\tilde{P}_{m}-\bar{P}_{m}\right)+\frac{1}{2}\left(\bar{\Gamma}_{222} \bar{P}_{m} C_{m}^{2}-2 \bar{\Gamma}_{22} C_{m}\right)\left(\tilde{P}_{m}-\bar{P}_{m}\right)^{2}\right]
$$

where the bars indicate that utility is evaluated at the expected price level. ${ }^{19}$ By taking expectations, (A1.4) becomes

$$
\begin{gathered}
E\left[\Gamma_{1}\right]=\bar{\Gamma}_{1}+\frac{1}{2} \bar{\Gamma}_{122} \sigma^{2} C_{m}^{2} \\
E\left[\tilde{P}_{m} \Gamma_{2}\right]=\bar{\Gamma}_{m} \bar{\Gamma}_{2}+\frac{1}{2} \bar{\Gamma}_{m} \bar{\Gamma}_{222} \sigma^{2} C_{m}^{2}-\sigma^{2} \bar{\Gamma}_{22} C_{m}
\end{gathered}
$$

Substituting (A1.5) into (A1.3) gives the first order condition expressed in terms of the first two moments of $\tilde{P}_{m}$ :

$$
\bar{\Gamma}_{1}+\frac{1}{2} \bar{\Gamma}_{122} \sigma^{2} C_{m}^{2}=\left(\bar{\Gamma}_{2}+\frac{1}{2} \bar{\Gamma}_{222} \sigma^{2} C_{m}^{2}\right) \bar{\Gamma}_{m}-C_{m} \sigma^{2} \bar{\Gamma}_{22}
$$

\footnotetext{
${ }^{19}$ For simplicity, we limit this demonstration to second order expansions. Froviding that the higher oriler derivatives of $\bar{\Gamma}$
exist, longer expansions still satisfy proposition A.l below.
} 
To find the pure substitution effect, $\frac{\partial C_{m}}{\partial \lambda}$, we take the total derivative of equation (A1.6) with respect to $\lambda$. The resulting expression contains derivatives of expected utility, and income and substitution effects. To eliminate the income effects, we approximate the level of expected utility by a Taylor series expansion,

$$
E[\Gamma] \approx \bar{\Gamma}+\frac{1}{2} \sigma^{2} C_{m}^{2} \bar{\Gamma}_{2}
$$

and take the derivative of (A1.7) with respect to $\lambda$ for a given level of expected utility. Combining the derivatives of equations (A1.6) and (A1.7) yields the pure substitution effect:

$$
\frac{\partial C_{m}}{\partial \lambda}=\left(\bar{\Gamma}_{11}-2 \bar{P}_{m} \bar{\Gamma}_{21}+\tilde{\Gamma}_{m}^{2} \bar{\Gamma}_{22}\right)^{-1}\left(\bar{\Gamma}_{2}+r_{p}^{2} \Psi\right)
$$

where the first term on the right-hand side is the certainty equivalent substitution effect, and $\Psi$ is $O(0)$ in $\tau_{p}$ :

$$
\begin{gathered}
\Psi=\frac{1}{2} \lambda(1-\lambda) C_{m}^{2}\left(\bar{\Gamma}_{1221}-2 \bar{P}_{m} \bar{\Gamma}_{1222}+\bar{P}_{m}^{2} \bar{\Gamma}_{2222}\right)+\lambda(1-\lambda) \Pi_{1}\left(2 C_{m}\left(\bar{\Gamma}_{122}-\vec{P}_{m} \bar{\Gamma}_{222}\right)+\bar{\Gamma}_{22}\right) \\
-\frac{1}{2} \lambda(1-\lambda) C_{m}^{2} \bar{\Gamma}_{222}+(1-2 \lambda)\left(\frac{1}{2} C_{m}^{2}\left(\bar{\Gamma}_{122}-\bar{P}_{m} \bar{\Gamma}_{222}\right)+C_{m} \bar{\Gamma}_{22}\right) \\
-\frac{(1-2 \lambda)\left(\frac{1}{3} C_{m}^{2} \bar{\Gamma}_{22}\right)\left(\bar{\Gamma}_{12}-\bar{P}_{m} \bar{\Gamma}_{22}+\frac{1}{2} \sigma^{2} C_{m}^{2}\left(\bar{\Gamma}_{1222}-\bar{P}_{m} \bar{\Gamma}_{2222}\right)+\sigma^{2} C_{m} \bar{\Gamma}_{222}\right)}{\bar{\Gamma}_{2}+\frac{1}{2} \sigma^{2} C_{m}^{2} \bar{\Gamma}_{222}}
\end{gathered}
$$

The sign and magnitude of $\Psi$ will depend upon the specific utility function chosen. Notice that, by continuing the Taylor serics expansions in equations (A1.4) and (A1.7) out beyond the second order, $\Psi$ would remain $O(0)$ in $\tau_{p}$. We then have:

Proposition A1. If $\Psi^{-1}<0$, then a necessary and sufficicnt condition for the own substitution effect to be negative is that $r_{p}^{2}<-\vec{\Gamma}_{2} \Psi^{-1}$. If $\Psi^{-1} \geq 0$, then no restriction on $\tau_{p}$ is required.

Proof. Note by inspection that if $\Psi \geq 0$, then the usual convexity assumptions imply that equation (A1.8) is negative. If, on the other hand, $\Psi<0$, the restriction in Proposition Al is necessary and sufficient. 


\section{Appendix 2}

Here we outline the conditions required to show that $\Delta$, the determinant on the right-hand side of (34), is negative. From equation (34) after collecting terms we have that

$$
\Delta=(F-\bar{\tau} B)+(N-a \lambda) \bar{\tau} V
$$

Since this appears of indeterminate sign some manipulation is recuired. First we show that, for small values of $\tau_{p}$

$$
F-\lambda \tau_{p} B<0
$$

Using the definitions in (35) we substitute into (A2.2)

$$
\Pi E_{22} \Pi-\lambda \tau_{p} \Pi_{1} E_{22} \Pi
$$

which then becomes:

$$
\Pi E_{22} \Pi\left(1-\frac{\lambda \tau_{p} C_{m}}{\Pi \Gamma}\right)
$$

which is unambiguously negative. The second term in $\Delta$ is unambiguously positive, so that we must again restrict $\tau_{p}$ :

$$
0<\tau_{p}<\frac{(F-\bar{\tau} B)}{-(N-a) V}
$$

to ensure that $\Delta$ is negative. 


\section{Appendix 3}

Here we give sufficient conditions that equation (36) is negative. First we demonstrate that the second term, which appears to be ambiguous in sign, is positive since $F C-B G>0$. Substituting from the definitions in (35) we have

$$
\left(\Pi E_{22} \Pi\right)\left(\Pi_{1} E_{22} \Pi_{1} D+E_{2} \Pi_{11}-Q_{11}\right)>\left(\Pi_{1} E_{22} \Pi\right)\left(D \Pi E_{22} \Pi_{1} D\right)
$$

Some algebra gives us an expression with only positive terms:

$$
\Pi E_{22} \Pi E_{2} \Pi_{11}+\Pi E_{22} \Pi Q_{11}>0
$$

The last term in equation (36), $\bar{\tau} V(\bar{\tau} C-G)$, is also ambiguous in sign. Once again a sufficient condition may be obtained to ensure that $\bar{\tau} V(\bar{\tau} C-G)$ is positive by restricting the size of the tariff:

$$
0<\tau_{p}<\frac{\Pi E_{22} \Pi}{\Pi_{1} E_{22} \Pi_{1} D+E_{2} \Pi_{11}-Q_{11}} .
$$




\section{References}

Calvo, Guillermo, "On the Time Consistency of Optimal Policy in a Monetary Economy,"
Econometrica, vol. 46 no 6., 1978. , "On the Costs of Temporary Liberalization / Stabilization Experiments," Columbia University, September 1985.

Diaz-Alejandro, Carlos, "Good-bye Financial Repression, Hello Financial Crash," Columbia
University, March, 1984.

Dornbusch, Rudiger, "Real Interest Rates, Home Goods and Optimal External Borrowing," Journal of Political Economy, vol. 91, no 1, pp. 141-53, February, 1983.

"External Debt, Budget Deficits and Disequilibrium Exchange Rates," in International Debt and the Deyeloping Countries, eds. G. Smith and J. Cuddington, Wash-
ington, D.C., The World Bank,

Edwards, Sebastian, "The Order of Liberalization of the Current and Capital Accounts of the Balance of Payments: A Survey of the Major Issues," The World Bank, 1983.

"The Order of Liberalization of the Extcmal Sector in Developing Countries," Princeton Papers in International Finance, 1985.

Experiment with Free Market Policies, 1073 ition: An Evaluation of Ten Years of Chile's Change, January, 1985.

Edwards, Sebastian and Sweder van Wijnbergen, "The Welfare Effects of Trade and Capital Market Liberalization: Consequences of Differcnt Sequencing Scenarios," NBER Working
Paper no. 1245, December, 1983 .

Frankel, J., K. Froot, and A. Mizala Salces, "Credibility, the Optimal Speed of Trade Liberalization, Real Interest Rates, and the Latin Amcrican Debt," The World Bank, July
1985. Krueger, Anne, Foreign Trade Regimes and Economic Development: Liberalization Attempts
and Consequences, Cambridge, MA, Ballinger, 1978.

"Problems of Liberalization," The World Bauk, 1983.

Krugman, Paul, "International Debt Stratcgies in an Uncertain World," in International Debt and the Developing Countries, eds. G. Smith and J. Cuddington, Washington, D.C., The
World Bank, 1985.

Little, Ian, Tibor Scitovsky, and M. Scott, Industry and Trade in Some, Developing Countries, 
Oxford University Press, 1970.

Martin, Ricardo and Marcelo Selowsky, "Encrgy Prices, Sulbstitution, and Optimal Borrowing in the Short Run: Au Analysis of Adjustment in Oil Importing Developing Countries," The World Bank, 1981.

McKinnon, Ronald, "The Order of Economic Liberalization: Lessons from Chile and Argentina," Carnogie-Rochester Conference Series on Public Policy, no. 17, pp. 159-86, 1982.

Mussa, Michael, "The Adjustment and the Timing of Trade Liberalization," The World Bank, 1983.

Obstfeld, Maurice, "Capital Flows, the Current Account and the Real Exchange Rate: Consequences of Liberalization and Stabilization," presented at the World Bank Conference on Exchange Rates and Developing Countries, November, 1984.

Razin, Assaf and Lars Svensson, "An Asymmetry Between Export and Import Taxes," Economic Letters, 1983.

Sachs, Jeffrey, "The Current Account and Macrocconomic Adjustment in the 1970s," Brookings Papers on Economic Activity, No. 1, pp. 201-68, 1081.

Svensson, Lars and Assaf Razin, "The Terms of Trade, Spending and the Current Account, the Harberger-Laursen-Metzler Effect," Journal of Political Economy, vol. 91, no. 1, 1983.

van Wijnbergen, Sweder, "Tariffs, Employment and the Current Account: The role of Real Wage Resistance," The World Bank, 1983.

"Trade Reform, Aggregate Investment and Capital Flight: On Credibility and the Value of Information," Economic Letters, 1985. 